Check for updates

Cite this: RSC Adv., 2017, 7, 24263

Received 20th March 2017 Accepted 26th April 2017

DOI: $10.1039 / c 7 r a 03277 c$

rsc.li/rsc-advances

\section{Synthesis, growth mechanism, optical properties and catalytic activity of ZnO microcrystals obtained via hydrothermal processing}

\author{
Edgar Alves Araújo Júnior,$\dagger^{\mathrm{a}}$ Francisco Xavier Nobre, $\hat{\dagger}^{\mathrm{b}}$ Giancarlo da Silva Sousa, ${ }^{a}$ \\ Laécio Santos Cavalcante, ${ }^{\mathrm{C}}$ Maria Rita de Morais Chaves Santos, ${ }^{a}$ \\ Flavio Leandro Souza $\dagger^{d}$ and José Milton Elias de Matos (D) $\dagger^{\star a}$
}

In the present study, typical $\mathrm{ZnO}$ microcrystals exhibiting the wurtzite hexagonal crystal structure were produced successfully, characterized by a high degree of crystallinity, via hydrothermal processing at 120, 150 and $180{ }^{\circ} \mathrm{C}$, assisted by $\mathrm{N}$-cetyl-N,N,N-trimethylammonium (CTAB). The samples were characterised by XRD, Raman and infrared, FE-SEM, UV-Vis by diffuse reflectance and photoluminescence (PL). The experimental results confirm that all hydrothermally synthesised $\mathrm{ZnO}$ samples were crystallised into a wurtzite hexagonal structure. The $\mathrm{ZnO}$ crystals exhibit the morphology of hexagonal columns in the absence and double hexagonal columns in the presence of CTAB. The length and average diameter of the microstructures decrease with increasing processing temperature. It is evident that all the synthesised samples present very similar profiles and band positions in the PL emission spectra, with an emission band in the violet range at approximately $400 \mathrm{~nm}$, a small peak in the UV range at approximately $380 \mathrm{~nm}$, and highly superposed and intense emission bands between 440 and $750 \mathrm{~nm}$ (blue to red emission), with a maximum at approximately $610 \mathrm{~nm}$. Furthermore, a nucleation and growth model was proposed to explain the formation of $\mathrm{ZnO}$ microcrystals, based on the experimental conditions, that were preferably grown in the [001] direction. In addition, the $\mathrm{ZnO}$ exhibited excellent performance in the photocatalytic degradation of rhodamine $\mathrm{B}(\mathrm{RhB})$ and methyl orange (MO), achieving $97 \%$ and $99 \%$ photodegradation of $\mathrm{RhB}$ and $\mathrm{MO}$, respectively, when $\mathrm{ZnO}$ obtained at $120{ }^{\circ} \mathrm{C}$, in the absence of CTAB, was used as catalyst.

\section{Introduction}

Zinc oxide $(\mathrm{ZnO})$ is a semiconductor material with a wide band gap (3.37 eV), large exciton binding energy $(60 \mathrm{meV})$ and singular electronic and optical properties that are particularly affected by the morphology and size of the crystals. ${ }^{1,2}$ Studies have demonstrated the versatility and potential capability of $\mathrm{ZnO}$ for a wide range of applications in photonic, photovoltaic and electronic devices, such as light-emitting diodes (LEDs), lasers, UV detectors, transistors and solar cells. ${ }^{3-9} \mathrm{ZnO}$ also

${ }^{a}$ Interdisciplinary Laboratory of Advanced Materials, LIMAV, Natural Sciences Centre, CCN, Department of Chemistry, Federal University of Piaui, Teresina, Piauí, 64049-550, Brazil. E-mail: jmematos@ufpi.edu.br; Tel: +55-086-3215-5840

${ }^{b}$ Laboratory of Research in Biology and Chemistry, LPBQ, Campus Coari, Federal Institute of Amazonas, IFAM, Road Coari-Itapéua, Coari, Itamaraty, AM, 69067-360, Brazil. Tel: + 55-097-3561-2470

${ }^{\prime}$ GERATEC, Natural Sciences Centre (Centro de Ciências da Natureza), University of State of Piaui (Universidade Estadual do Piaui), Teresina, Piaui, 64002-150, Brazil ${ }^{d}$ Natural and Human Sciences Centre (Centro de Ciências Naturais e Humanas $C C N H$ ), Federal University of $A B C$ (Universidade Federal do $A B C$ ), 09210-170 Santo André, SP, Brazil

$\dagger$ These authors contributed equally to this work. exhibits interesting piezoelectric properties that permit its application as transducers and surface acoustic wave (SAW) and bulk acoustic wave (BAW) devices. ${ }^{10,11}$ Furthermore, especially in the form of powder, $\mathrm{ZnO}$ can be applied to pigments, ${ }^{\mathbf{1 2}}$ photo(catalysts). ${ }^{\mathbf{1 3} 14}$ and UV radiation attenuators. ${ }^{15}$ Because of its excellent UV attenuation properties, $\mathrm{ZnO}$ can also be used in cosmetics, paints, varnish and plastics. ${ }^{\mathbf{1 0 , 1 6 , 1 7}}$ In the last five year, $\mathrm{ZnO}$ has gained especial attention as antimicrobial agent ${ }^{5,18}$ and in cancer therapy due it ability to distinguish between normal and cancers cells. ${ }^{19,20}$ Additionally, $\mathrm{ZnO}$ can be used as an antimicrobial agent. .,18 $^{\text {An }}$

Powder ZnO can be synthesised using various synthesis methods that are well established in the literature, such as zinc oxidation from metallic zinc vapour, through the French or American process, ${ }^{21}$ decomposition of salts containing zinc, ${ }^{22}$ spray pyrolysis, ${ }^{23}$ sol-gel ${ }^{24,25}$ and coprecipitation. ${ }^{26,27}$ Most of these methods employ high temperatures up to $1000{ }^{\circ} \mathrm{C}$ to crystallise the $\mathrm{ZnO}$ phase. In such cases, the high processing temperatures lead to the excessive formation of aggregates in the ZnO powder, which results in little control over the morphology and particle size distribution. ${ }^{10}$ 
In turn, the hydrothermal processing crystallises anhydrous materials directly from aqueous solutions at temperatures higher than room temperature, usually between 100 and $300{ }^{\circ} \mathrm{C}$, and pressures higher than normal pressures to obtain a fine powder under the corresponding saturated water vapour pressures. ${ }^{28}$ Among the various physical and chemical material preparation methodologies (bottom-up), the chemical method for material preparation from an aqueous solution maintained at hydrothermal conditions offers numerous advantages to large-scale production such as: (i) the performance of singlestage synthesis, with no subsequent calcination and grinding; (ii) low aggregation level, (iii) narrow crystallite size distribution; and (iv) high purity with excellent control of morphology and particle size. ${ }^{6,29}$ This method offers many advantages over the conventional synthesis methods, such as the performance of single-stage synthesis, with no subsequent calcination and grinding, a low aggregation level and a narrow crystallite size distribution, as well as high purity and excellent control of the morphology and particle size. ${ }^{6,29}$ The hydrothermal processing conditions often result in chemical structures with unique structure defects that cannot be generated using the classical methods, which use very high processing temperatures; therefore, these conditions can result in materials with exclusive properties. $^{30,31}$ The processing is called solvothermal when water is not used as the solvent and presents the same advantages as the hydrothermal processing method. ${ }^{32}$ Solvothermal synthesis of materials is normally used when there is the need for strict control of the particle size and shape and avoids premature agglomeration. However, from the economical viewpoint, the synthesis processes at hydrothermal conditions (water as the solvent) involve simpler equipment and fast and efficient residue removal compared with the process performed exclusively in organic solvents.

For instance, control nanomaterial size and morphology has been intensively investigated in terms of photocatalysis application. Among several materials for this purpose $\mathrm{ZnO}$ and $\mathrm{TiO}_{2}$ are two of the most popular photocatalysts used for organic pollutant degradation, ${ }^{33-35}$ water waste treatment, ${ }^{36-39}$ clean fuel production $^{\mathbf{4 0 - 4 2}}$ and so on. Adhikari et al., showed an effective degradation of methyl orange under visible light irradiation by using a quasi-fibrous morphology of $\mathrm{ZnO}$ powder synthesized by combustion process. ${ }^{43}$ Fang and coworkers ${ }^{44}$ compared the performance on methyl orange photodegradation using sphere and flower-like $\mathrm{ZnO}$ morphology obtained at temperature below $200{ }^{\circ} \mathrm{C}$ under hydrothermal condition. The spherical $\mathrm{ZnO}$ morphology resulted in a superior photocatalytic activity compared with flower-like $\mathrm{ZnO}$ and commercial ones, which was attributed to a higher specific area and existence of more available oxygen vacancies. ${ }^{\mathbf{4 4}}$ More recently, Wolski et al. $^{\mathbf{4 5}}$ demonstrated that the high surface area provided by the spherical zinc oxide morphology is less important than crystallinity degree and defect density towards the photodegradation efficiency of rhodamine B. Therefore, a sufficient area should be required to guarantee the total photodegradation of the rhodamine $\mathrm{B}$, otherwise only partial conversion of the pollutant can be reach in a short period of irradiation. Indeed, the photocatalytic activity is governates by a compromise in between synthetic method and final properties by a fine control of several parameters such as, size, morphology, surface area, defect density, etc. Based on the literature report history seems that the key factor for higher photocatalytic activity is not the same for the available materials, which open avenues for intensive and detailed investigation in this field to achieve a better method and material for this application..$^{8-45}$

In the present study, surfactant-assisted hydrothermal processing was applied for the synthesis of $\mathrm{ZnO}$ microcrystals at mild temperatures. The $N$-cetyl- $N, N, N$-trimethylammonium bromide (CTAB) cationic tensioactive has been used in hydrothermal synthesis to favour the growth and orientation of $\mathrm{ZnO}$ crystals, ${ }^{46}$ and in this study, its effect on the morphology and size of $\mathrm{ZnO}$ microcrystals is investigated. The $\mathrm{ZnO}$ wurtzite phase is not centrosymmetric, as it exhibits polar crystalline faces, ${ }^{47}$ which is significant for crystal growth. For various applications, the structure of $\mathrm{ZnO}$ should be investigated, and its growth behaviour should be controlled. The growth pattern, size and morphology of the $\mathrm{ZnO}$ crystal structures obtained by the hydrothermal method are usually affected by the $\mathrm{pH}$, presence of additives, processing temperature and concentration of reagents. ${ }^{48}$ We also evaluated the photocatalytic activity of $\mathrm{ZnO}$ in degradation of rhodamine $\mathrm{B}$ (RhB) and methyl orange (MO) under visible light irradiation.

\section{Experimental}

\subsection{ZnO synthesis by the hydrothermal method}

The ZnO crystals were synthesised by the hydrothermal method in alkaline medium. The starting materials were as follows: zinc acetate dihydrate $(\mathrm{ZAD})\left[\mathrm{Zn}\left(\mathrm{CH}_{3} \mathrm{COO}\right)_{2} \cdot 2 \mathrm{H}_{2} \mathrm{O}\right](>98 \%$, Vetec), sodium hydroxide $[\mathrm{NaOH}](97 \%$, Sigma-Aldrich), CTAB $\left[\mathrm{C}_{19} \mathrm{H}_{42} \mathrm{BrN}\right](>99 \%$, Vetec) and distilled water. All the reagents were of analytical grade and were used with no previous purification.

Approximately $6.0 \mathrm{~g}$ of ZAD and $4.5 \mathrm{~g}$ of CTAB were weighed and transferred to stainless steel-coated polytetrafluoroethylene (PTFE) autoclaves with screw lids. Next, $100 \mathrm{~mL}$ of $0.3 \mathrm{M} \mathrm{NaOH}$ solution was added, and manual agitation was performed using a glass stirring rod for $10 \mathrm{~min}$. Then, the autoclaves were sealed with proper lids and transferred to an oven (Quimis, Q819V), where they remained for $24 \mathrm{~h}$ at different temperatures (120, 150 and $180{ }^{\circ} \mathrm{C}$ ). After the reaction period, the solutions were washed with distilled water and ethyl alcohol (95\%, Vetec) in a centrifuge (Sigma, 3-16L) at $3000 \mathrm{rpm}$. The samples were dried in an oven (Odontobras, EL 1.1) at $75^{\circ} \mathrm{C}$ for approximately $8 \mathrm{~h}$.

\subsection{Characterisation}

The samples were characterised by X-ray diffraction (XRD) using a Shimadzu diffractometer, model XRD6000 (Japan) using Cu$\mathrm{K} \alpha$ radiation $(\lambda=1.54056 \AA)$ at $40 \mathrm{kV}$ and $30 \mathrm{~mA}$. The tests were performed with a step size of $0.02^{\circ}$ between 10 and $110^{\circ}(2 \theta)$ with a scan rate of $0.5^{\circ}$ per minute in continuous mode. The XRD patterns of the samples were refined using the Rietveld method using the DBWSTools program. The refinement 
procedure consisted primarily of adjusting the displacement parameters of the sample relative to the crystal plane, background, scale factor, full-width at half-maximum of the diffraction peak $(W)$, asymmetry factor, peak profile (NA and $\mathrm{NB})$, lattice parameters $(a, b, c ; \alpha, \beta, \gamma)$, possible preferential orientation, atomic positions $(x, y, z)$, isotropic or anisotropic thermal parameters, and instrumental parameters $(U$ and $V)$. The special atomic positions were not refined as they are intrinsic parameters of the sample.

The Raman spectra were collected using a Bruker Senterra monochromator (Germany) coupled to an Olympus BX50 microscope, connected to a CCD (charge-coupled device) detector, with automatic resolution adjustment at $0.1 \mathrm{~cm}^{-1}$. The readings were performed at room temperature from 35 to 1555 $\mathrm{cm}^{-1}$ using a laser with an excitation wavelength of $532 \mathrm{~nm}$, with output power of $20 \mathrm{~mW}$ and an integration time of $10 \mathrm{~s}$. The measurements in the infrared (IR) region were obtained using a Bruker spectrometer, model Vertex 70 (Germany) in the range from 4000 to $400 \mathrm{~cm}^{-1}$, with 32 scans for each measurement and a resolution of $4 \mathrm{~cm}^{-1}$.

The morphology of the $\mathrm{ZnO}$ particles was investigated using field-emission scanning electron microscopy (FE-SEM) using an FE-SEM-FEI microscope, model Inspec F-50. From the FE-SEM images, the particle size distribution was estimated, and the morphology was examined.

Diffuse reflectance $(R)$ UV-Vis spectra were registered using a Varian spectrophotometer, model Cary 5G (United States), with wavelengths ranging between 200 and $800 \mathrm{~nm}$. Magnesium oxide (MgO) was used as the reference material, and a special sample holder was adapted for powders. The photoluminescence (PL) measurements were performed in a Monospec 27 monochromator from Thermal Jarrel Ash (United States), coupled to a R446 photomultiplier from Hamamatsu Photonics (Japan), with an SR-530 lock-in acquisition system. A krypton ion laser of $350.7 \mathrm{~nm}$ from Coherent Innova $90 \mathrm{~K}$ (United States) was used as the excitation source, maintaining its maximum power at $200 \mathrm{~mW}$.

\subsection{Photocatalytic activity}

The photocatalytic experiments were conducted using $100 \mathrm{~mL}$ of dye solution (RhB and $\mathrm{MO}$ ) at a concentration of $1.0 \times$ $10^{-5} \mathrm{~mol} \mathrm{~L}^{-1}$, added in a quartz reactor $600 \mathrm{~mL}$ under magnetic stirring and an average temperature of $25.0 \pm 0.5{ }^{\circ} \mathrm{C}$. Subsequently, inserted for each catalytic test, $100 \mathrm{mg}$ of the catalyst, which remained under magnetic stirring for 5 minutes, followed by stirring in an ultrasound tub Cristófoli mark A52243ZZZ110V code, with a frequency of $42 \mathrm{kHz}$ for 10 minutes in order to obtain the adsorption equilibrium in solution. The emulsion obtained was inserted in a photocatalytic system consisting of a wooden box with two coupled microfan (1.5 A and $12 \mathrm{~V}$ ), six UVC lamps (Osram $15 \mathrm{~W}$ ) with a wavelength of $253.7 \mathrm{~nm}$, a magnetic stirrer and an aquarium pump with a flow rate of $1.8 \mathrm{~L} \mathrm{~min}{ }^{-1}$. The monitoring of catalytic activity was carried out by removing $4 \mathrm{~mL}$ of the solution followed by centrifugation of $5000 \mathrm{rpm}$ for 10 minutes, analyzing the wavelength of maximum absorption of the supernatant, the latter being $554 \mathrm{~nm}$ and $465 \mathrm{~nm}$, corresponding to RhB dyes and $\mathrm{MO}$, respectively. Operating a spectrophotometer brand Thermo Scientific GENESYS 10S model, conducting sweeps in the range of $200 \mathrm{~nm}$ to $900 \mathrm{~nm}$, with $10 \mathrm{~nm} \mathrm{~s}^{-1}$ by adding solutions in quartz cuvettes.

\section{Results and discussion}

\subsection{XRD and Rietveld refinement}

Fig. 1 presents the diffractograms of the $\mathrm{ZnO}$ microcrystals synthesised by the hydrothermal method for $24 \mathrm{~h}$ at 120,150 and $180{ }^{\circ} \mathrm{C}$, with and without the assistance of CTAB. The position of the peaks in all the diffractograms presented in Fig. 1 have the same pattern, regardless of the preparation conditions of the ZnO powder. This pattern confirms that the crystal structure of the samples is hexagonal (wurtzite), with $C_{6 v}{ }^{4}$ or $P 6_{3} m c$ spatial group and crystallographic class $6 \mathrm{~mm}$, according to the respective crystallographic card ICSD no. 34477 $\left(\right.$ ICSD $=$ Inorganic Crystal Structure Database) ${ }^{49}$ Intermediate crystal phases were not observed, indicating the high purity of these materials obtained in a single stage at hydrothermal conditions. The presence of defined and intense peaks indicates that the ZnO powders exhibit high crystallinity (structural periodicity) and are structurally ordered at a long distance.

Once the crystallography phase $\mathrm{ZnO}$ was confirmed, the XRD results underwent the refinement process by the Rietveld method using the DBWS Tools software interface. The data on crystallographic pattern profiles of the wurtzite phase is available on the Capes Research Website ${ }^{50}$ from the International Center for Diffraction Data (ICDD). The ICSD no. 34477 (ref. 49) card was used.

Table 1 presents the lattice parameters and the unit cell volume of the $\mathrm{ZnO}$ samples, which were calculated after the structural refinement and compared with the data reported in the literature..$^{51-57}$ The slight variations on the experimental

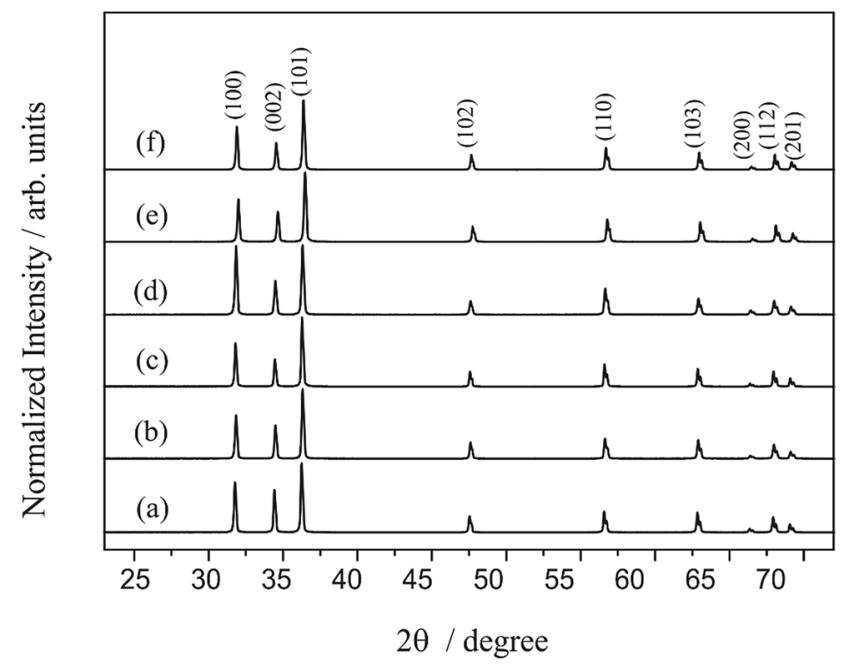

Fig. 1 XRD patterns of $\mathrm{ZnO}$ synthesized hydrothermally for $24 \mathrm{~h}$ at $120^{\circ} \mathrm{C}$ (a) without and (b) with $\mathrm{CTAB}$, at $150^{\circ} \mathrm{C}$ (c) without and (d) with $\mathrm{CTAB}$, and at $180^{\circ} \mathrm{C}$ without (e) and (f) with CTAB. 
Table 1 Comparative results between the lattice parameters and unit cell volume of the hydrothermally processed $\mathrm{ZnO}$ microcrystals in this study, with data reported in the literature, using different synthesis methods and information on bulks ${ }^{a}$

\begin{tabular}{|c|c|c|c|c|c|c|c|}
\hline & \multirow[b]{2}{*}{$T\left({ }^{\circ} \mathrm{C}\right)$} & \multirow[b]{2}{*}{$t(\mathrm{~h})$} & \multicolumn{2}{|c|}{$\begin{array}{l}\text { Lattice parameters } \\
(\AA)\end{array}$} & \multirow[b]{2}{*}{$V\left(\AA^{3}\right)$} & \multirow[b]{2}{*}{ JCPDS } & \multirow[b]{2}{*}{ Ref } \\
\hline & & & $a=b$ & $c$ & & & \\
\hline \multicolumn{8}{|c|}{ Synthesis methods } \\
\hline HT & 140 & 24 & 0.3249 & 0.5206 & - & $36-1451$ & 32 \\
\hline HT & 150 & 24 & 0.3249 & 0.5206 & - & $36-1451$ & 51 \\
\hline HT & 140 & 12 & 0.3242 & 0.5188 & - & 79-0205 & 52 \\
\hline SG & 80 & 24 & 0.324 & 0.519 & 54.5 & $36-1451$ & 24 \\
\hline HT & 140 & 12 & 0.3251 & 0.5206 & - & $79-2205$ & 53 \\
\hline HT & 180 & 24 & 0.3249 & 0.5205 & - & $75-0576$ & 46 \\
\hline $\mathrm{HT}$ & 120 & 5 & 0.32508 & 0.52069 & - & $36-1451$ & 54 \\
\hline $\mathrm{CP}$ & 60 & 2 & 0.3250 & 0.5207 & - & $36-1451$ & 55 \\
\hline
\end{tabular}

Lattice parameters

(̊)

$a=$

$c$

$V\left(\AA^{3}\right) \quad$ JCPDS Ref.

\section{Bulks}

BK - ICSD no. 34477

BK - ICSD no. 57450

\begin{tabular}{lllll}
0.32498 & 0.52066 & 47.623 & - & 56 \\
0.3253 & 0.5213 & 47.77 & - & 49 \\
0.32494 & 0.52038 & 47.59 & - & 59 \\
\hline
\end{tabular}

Lattice

parameters $(\AA)$

$T\left({ }^{\circ} \mathrm{C}\right)$

$a=b \quad c$

$V\left(\AA^{3}\right) \quad$ JCPDS

CTAB

\section{This study}

HT 120

HT 120

24

\subsection{1}

0.3252

0.5207

47.66

36-1451

0.5207

47.70

$36-1451$

$36-1451$

$\begin{array}{ll}0.3252 & 0.5209 \\ 0.3250 & 0.5208\end{array}$

47.70

$0.2513 \quad 0.5209$

47.65

$36-1451$

47.69

$36-1451$

0.3250

0.5207

47.64
BK - ICSD no. 26170

Table 2 Atomic coordinates obtained from the Rietveld refinement data for $\mathrm{ZnO}$ crystals synthesised for $24 \mathrm{~h}$ at 120,150 and $180^{\circ} \mathrm{C}$, with and without the assistance of CTAB

\begin{tabular}{lllll}
\hline Atoms & Wyckoff & Sites & $x$ & $y$ \\
\hline
\end{tabular}

\section{$120{ }^{\circ} \mathrm{C}$, CTAB: no}

$\begin{array}{llllll}\text { Zinc } & 2 \mathrm{~b} & 3 \mathrm{~m} & 0.3333 & 0.6667 & 0\end{array}$

$\begin{array}{llllll}\text { Oxygen } & 2 \mathrm{~b} & 3 \mathrm{~m} & 0.3333 & 0.6667 & 0.3917\end{array}$ Density $=5.667 \mathrm{~g} \mathrm{~cm}^{-3} ; R_{\mathrm{p}}=9.56 \% ; R_{\mathrm{wp}}=12.28 \% ; R_{\exp }=5.14 \%$ and $S$ $=2.39$

\begin{tabular}{|c|c|c|c|c|c|}
\hline \multicolumn{6}{|c|}{$120^{\circ} \mathrm{C}$, CTAB: yes } \\
\hline Zinc & $2 \mathrm{~b}$ & $3 \mathrm{~m}$ & 0.3333 & 0.6667 & 0 \\
\hline Oxygen & $2 b$ & $3 \mathrm{~m}$ & 0.3333 & 0.6667 & 0.3857 \\
\hline \multicolumn{6}{|c|}{$\begin{array}{l}\text { Density }=5.674 \mathrm{~g} \mathrm{~cm}^{-3} ; R_{\mathrm{p}}=7.06 \% ; R_{\mathrm{wp}}=10.15 \% ; R_{\exp }=5.29 \% \text { and } S \\
=1.92\end{array}$} \\
\hline \multicolumn{6}{|c|}{$150{ }^{\circ} \mathrm{C}$, CTAB: no } \\
\hline Zinc & $2 b$ & $3 \mathrm{~m}$ & 0.3333 & 0.6667 & 0 \\
\hline Oxygen & $2 b$ & $3 \mathrm{~m}$ & 0.3333 & 0.6667 & 0.3818 \\
\hline
\end{tabular}

\section{$150{ }^{\circ} \mathrm{C}, \mathrm{CTAB}:$ yes}

$\begin{array}{llllll}\text { Zinc } & 2 \mathrm{~b} & 3 \mathrm{~m} & 0.3333 & 0.6667 & 0\end{array}$

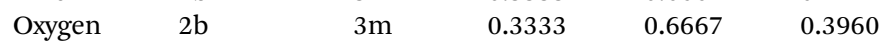
Density $=5.674 \mathrm{~g} \mathrm{~cm}^{-3} ; R_{\mathrm{p}}=12.37 \% ; R_{\mathrm{wp}}=14.96 \% ; R_{\exp }=5.04 \%$ and $S$ $=2.96$

\begin{tabular}{|c|c|c|c|c|c|}
\hline \multicolumn{6}{|c|}{$180{ }^{\circ} \mathrm{C}$, CTAB: no } \\
\hline Zinc & $2 \mathrm{~b}$ & $3 \mathrm{~m}$ & 0.3333 & 0.6667 & 0 \\
\hline Oxygen & $2 b$ & $3 \mathrm{~m}$ & 0.3333 & 0.6667 & 0.3806 \\
\hline \multicolumn{6}{|c|}{$\begin{array}{l}\text { Density }=5.669 \mathrm{~g} \mathrm{~cm}^{-3} ; R_{\mathrm{p}}=6.95 \% ; R_{\mathrm{wp}}=10.53 \% ; R_{\exp }=5.59 \% \text { and } S \\
=1.88\end{array}$} \\
\hline \multicolumn{6}{|c|}{$180{ }^{\circ} \mathrm{C}$, CTAB: yes } \\
\hline Zinc & $2 \mathrm{~b}$ & $3 \mathrm{~m}$ & 0.3333 & 0.6667 & 0 \\
\hline Oxygen & $2 b$ & $3 \mathrm{~m}$ & 0.3333 & 0.6667 & 0.3812 \\
\hline $\begin{array}{l}\text { Density } \\
S=1.95\end{array}$ & & & $R_{\mathrm{wp}}=1$ & $\% ; R_{\exp }=$ & \\
\hline
\end{tabular}

${ }^{a} T=$ temperature; $t=$ processing time; $a, b, c=$ lattice parameters; $V=$ unit cell volume; JCPDS = Joint Committee on Powder Diffraction Standards; ICSD = Inorganic Crystal Structure Database; Ref. = reference; $\mathrm{pH}=\mathrm{pH}$ value; $\mathrm{CT}=$ presence or absence of CTAB (cetyl trimethylammonium bromide); $\mathrm{N}=$ no; $\mathrm{Y}=$ yes; $\mathrm{HT}=$ hydrothermal; $\mathrm{SG}=$ sol-gel; $\mathrm{CP}=$ coprecipitation; $\mathrm{BK}=$ bulk.

results may be related to the different types of synthesis methods and experimental conditions, such as the processing temperature, heating rate, reaction time, atmosphere, solvent, etc., which, consequently, may generate different levels of longrange structural organisation in the hexagonal lattice.

The complete results of the structural refinement by the Rietveld method are presented in Table 2, with the following Rietveld refinement results: density and unit cell volume, atomic positions $(x, y, z)$ and refinement quality indexes $\left(R_{\mathrm{p}}\right.$, $R_{\mathrm{wp}}, R_{\text {exp }}$, and $S$ ). Table 2 presents the numerical quality indicators of structural refinement using the Rietveld method. $S$ parameter values smaller than 2 indicate satisfactory refinement; ${ }^{58}$ the samples maintained at $180{ }^{\circ} \mathrm{C}$ in hydrothermal conditions exhibited values of $S=1.88$ and 1.95 , with and without the assistance of CTAB, respectively.
The Rietveld refinement calculations for the $\mathrm{ZnO}$ microcrystals hydrothermally processed at $180^{\circ} \mathrm{C}$, with and without the assistance of $\mathrm{CTAB}$, are presented in Fig. 2. The results indicate good agreement between the profiles of the experimental diffractograms and the theoretical data for the $\mathrm{ZnO}$ wurtzite structure. The differences between the diffractogram profiles $\left(Y_{\text {observed }}-Y_{\text {calculated }}\right)$ are small on the scale of intensity.

In turn, the samples synthesised at 120 and $150{ }^{\circ} \mathrm{C}$, in the presence and absence of CTAB, exhibited high $S$ values because $R_{\text {exp }}$ was smaller. Nevertheless, the refinements can be considered of good quality, as the value of $R_{\exp }$ is lower because of the high intensities. Consequently, the value of $S$ becomes higher than 2 for such cases, which also has been reported in literature (ex.: $S=3.31) .^{59}$

According to Young, ${ }^{60}$ although the numerical indicators are important for the refinements by maximum likelihood, it is vital to perform the graph fitting analysis by the line of differences between the observed and calculated data. 

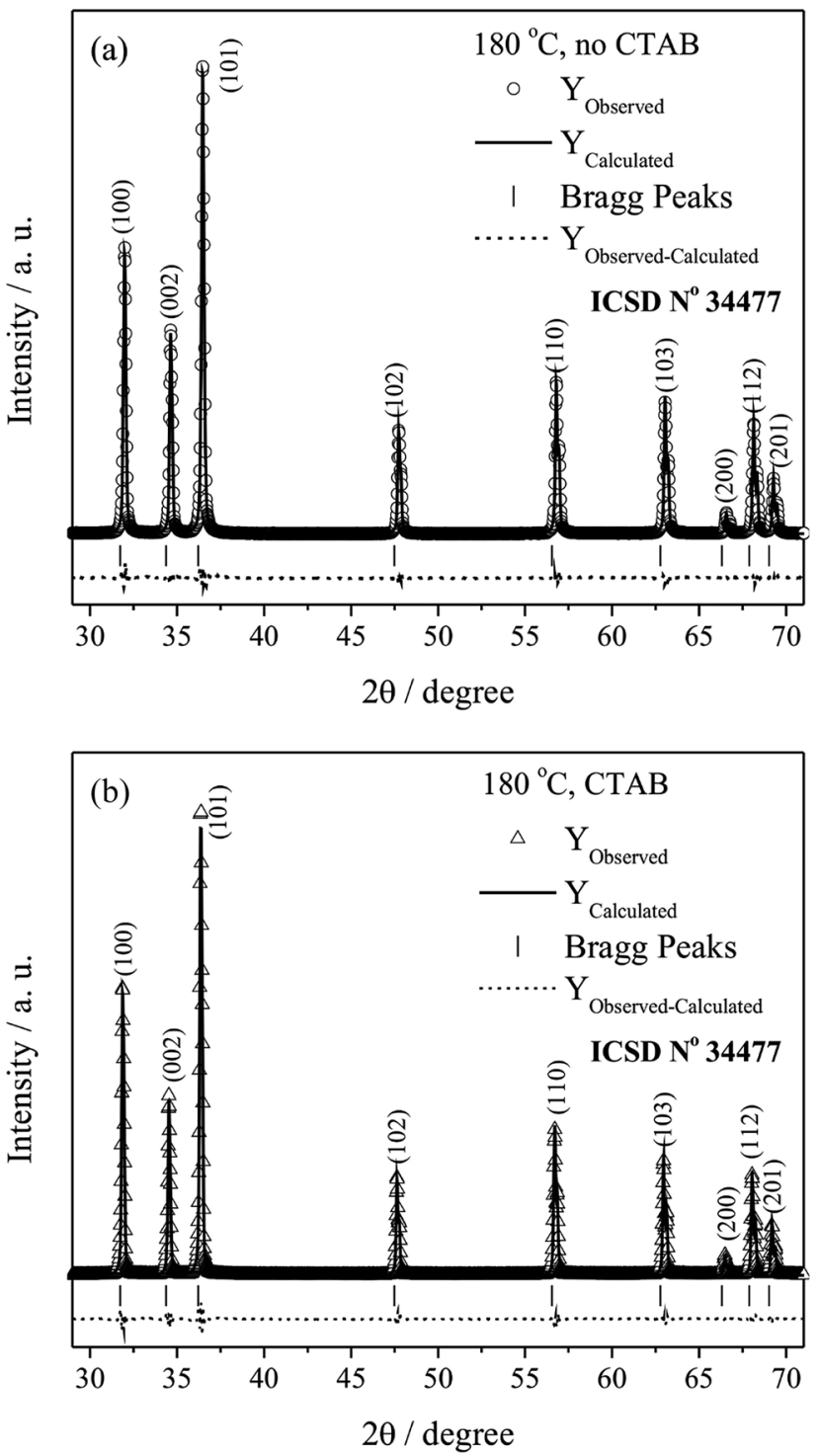

Fig. 2 XRD pattern refinements using the Rietveld method of $\mathrm{ZnO}$, (a) without and (b) with the assistance of CTAB, at $180^{\circ} \mathrm{C}$.

\subsection{Unit cells representation}

Fig. 3 presents schematic representations for the unit cells of the $\mathrm{ZnO}$ microcrystals hydrothermally processed at $180{ }^{\circ} \mathrm{C}$ for $24 \mathrm{~h}$, with and without the assistance of CTAB, from the structural refinement data obtained using the Rietveld method. The unit cells were modelled using the Diamond Crystal and Molecular Structure Visualisation program, demo version 3.2f for Windows, ${ }^{61}$ using the atomic coordinates calculated by the Rietveld refinement, displayed in Table 2.

Some interesting characteristics are observed in the unit cells presented in Fig. 3, such as: (i) the unit cell contains four atoms, two of each type ( $\mathrm{Zn}$ and $\mathrm{O}$ ); each atom is tetrahedrally coordinated in the crystal lattice, with hexagonal symmetry; and (ii) the two types of atoms occupy a sublattice throughout the $c$ axis. In fact, this type of structure is composed by two compact hexagonal sublattices, where the layers occupied by $\mathrm{Zn}$ atoms (a)

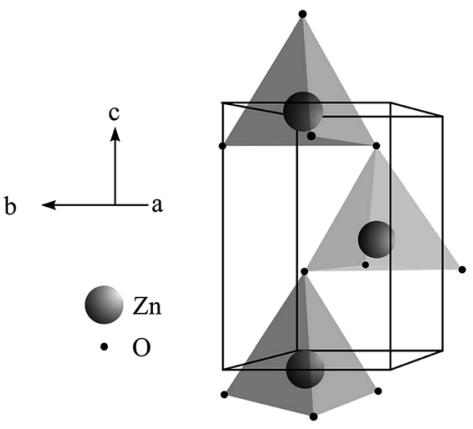

(b)

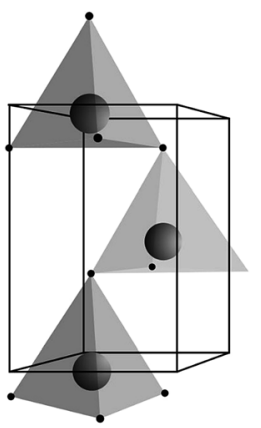

Fig. 3 Modeling of unit cells of $\mathrm{ZnO}$ microcrystals synthesized hydrothermally at $180^{\circ} \mathrm{C}$, for $24 \mathrm{~h} \mathrm{(a)} \mathrm{without} \mathrm{and} \mathrm{(b)} \mathrm{with} \mathrm{CTAB.}$

alternate with the layers occupied by $\mathrm{O}$ atoms around the $c$ axis. In every sublattice, four atoms are included per unit cell, for instance, each $\mathrm{Zn}$ atom is coordinated to four $\mathrm{O}$ atoms, or vice versa. Hence, half of the tetrahedral sites are occupied by $\mathrm{Zn}$ atoms.

The unit cell volume is approximately $47.6 \AA^{3}$. Consequently, ZnO contains approximately $8.4 \times 10^{22}$ atoms per $\mathrm{cm}^{3}$. The synthetically produced $\mathrm{ZnO}$ with the wurtzite structure may eventually exhibit a crystallographic arrangement different from the pattern established in the crystallographic records. A characteristic of this type of hexagonal crystalline arrangement is the $c / a$ ratio between the unit cell parameters, which was determined to be 1.63 for the ideal arrangement, considering the atomic positions $(x, y, z)$ and maximum packing..$^{62}$ Generally, the main reasons that the synthetic materials differ from the ideal arrangement are related to the methodology of preparation, which depends on external factors such as the pressure and temperature, time, and presence of impurities, among others. ${ }^{62}$ In the real $\mathrm{ZnO}$ crystal, the wurtzite structure diverges from the ideal arrangement because the $c / a$ ratio varies. Although the ideal wurtzite structure exhibits a $c / a$ ratio of $1.63,{ }^{62}$ the lattice constants of the real $\mathrm{ZnO}$ structure depend on impurities, external factors, temperature, etc.

\subsection{Raman and IR spectroscopy}

The structural lattice of the $\mathrm{ZnO}$ wurtzite phase consists of a basic unit of four atoms per unit cell (two $\mathrm{Zn}-\mathrm{O}$ molecular units). Because of the number $n=4$ atoms in the unit cell, the number of phonons is equivalent to $3 n=12$, with 3 acoustic modes $(1 \times$ LA, $2 \times$ TA $)$ and $3 n-3=9$ optical phonons $(3 \times$ LO, $6 \times$ TO). In the $\Gamma$ point of the Brillouin zone, the optical phonons have irreducible representation:

$$
\Gamma(\text { Raman }+ \text { infrared })=1 \mathrm{~A}_{1}+2 \mathrm{~B}_{1}+1 \mathrm{E}_{1}+2 \mathrm{E}_{2},
$$

whereas the $\mathrm{E}$ modes are doubly degenerated. The $\mathrm{B}_{1}$ modes are silent modes, i.e., inactive in the Raman and infrared spectra, and the $\mathrm{E}_{2}$ modes are only active in the Raman spectra. Modes $\mathrm{A}_{1}$ and $\mathrm{E}_{1}$, active in the Raman and infrared spectra, are polar. Therefore, each one is divided into longitudinal (LO) and 


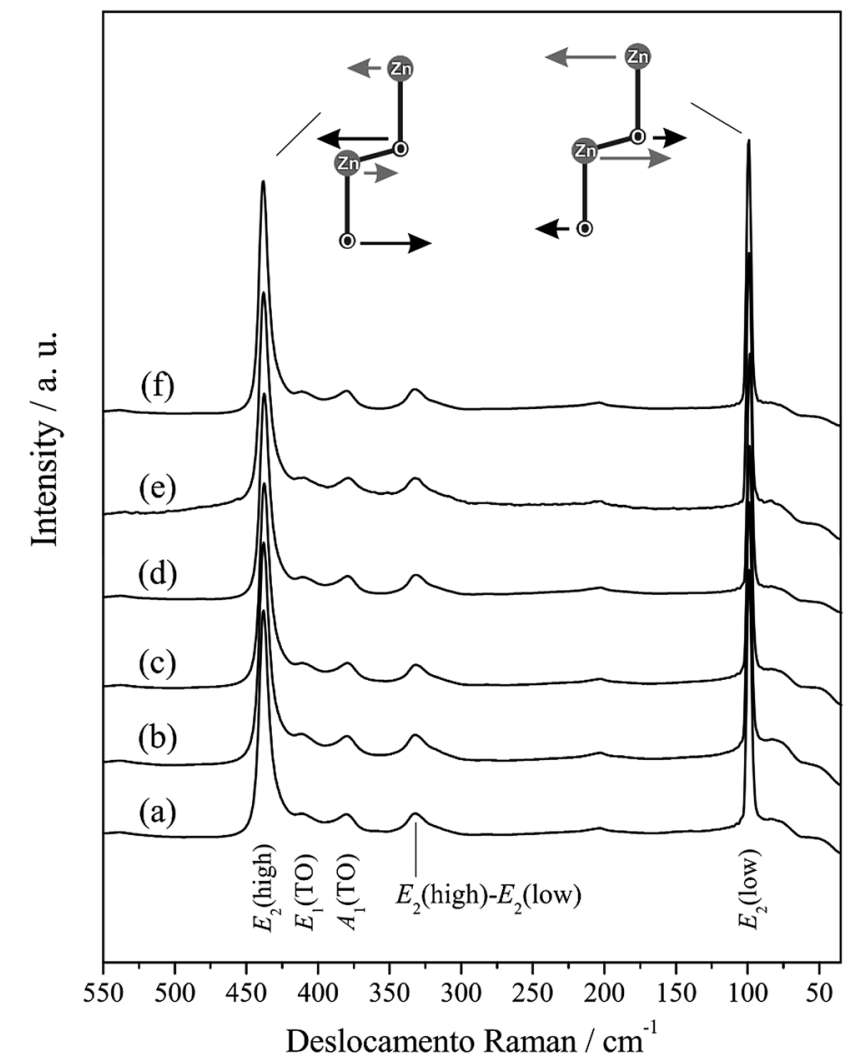

Fig. 4 Raman spectra of $\mathrm{ZnO}$ processed hydrothermally for $24 \mathrm{~h}$ at $120^{\circ} \mathrm{C}$ (a) without and (b) with $\mathrm{CTAB}$, at $150^{\circ} \mathrm{C}$ (c) without and (d) with $\mathrm{CTAB}$ and $180^{\circ} \mathrm{C}$ without (e) and (f) CTAB. The $\mathrm{E}_{2}$ modes(low) and $\mathrm{E}_{2}$ (high) are shown in figure.

transversal (TO) optical modes caused by macroscopy electric field of phonons localized at LO, which are represented by the Raman mode in the range of wavenumber from 98 to $591 \mathrm{~cm}^{-1}$.

Fig. 4 presents the Raman spectra for the $\mathrm{ZnO}$ microcrystals synthesised for $24 \mathrm{~h}$ at 120,150 and $180{ }^{\circ} \mathrm{C}$, with and without the assistance of CTAB. The band position, attribution and main Raman modes reported in the literature of $\mathrm{ZnO}$ crystals obtained by different synthesis, bulk and theoretical methods are listed in Table $3 .^{5,11,16,26,63-73}$

The modes present in the Raman spectra of the ZnO samples investigated in this study were attributed to the wurtzite crystal structure. The intense $\mathrm{E}_{2}$ (low) band, approaching $100 \mathrm{~cm}^{-1}$, is attributed to the vibrations of the $\mathrm{Zn}$ sublattice in the $\mathrm{ZnO}$ structure. The bands close to 330 and $380 \mathrm{~cm}^{-1}$ are attributed to modes $\mathrm{E}_{2}$ (high) $-\mathrm{E}_{2}$ (low) (second-order acoustic) and $\mathrm{A}_{1}(\mathrm{TO})$, respectively. Almost unnoticeable, the weak band approaching $200 \mathrm{~cm}^{-1}$ refers to mode $2 \mathrm{E}_{2}$ (low). An evident and strong peak is present in all the spectra at approximately $440 \mathrm{~cm}^{-1}$, which is characteristic of the scattering of the $\mathrm{ZnO}$ hexagonal wurtzite dominant mode $\mathrm{E}_{2}$ (high) and is attributed to the vibration of the sublattice of $\mathrm{O}$. Additionally, the literature reports that mode $\mathrm{E}_{2}$ (high) exhibits excellent crystallinity ${ }^{74}$ and acts as a signature of the $\mathrm{ZnO}$ wurtzite phase, which demonstrates the good correlation with the XRD data for all the $\mathrm{ZnO}$ microcrystals synthesised at hydrothermal conditions.
Table 3 Comparison among the main Raman active modes for $\mathrm{ZnO}$ crystals obtained in this study and other studies reported in the literature obtained by different synthesis, bulk and theoretical methods ${ }^{a}$

\begin{tabular}{|c|c|c|c|c|c|c|c|}
\hline & \multirow[b]{2}{*}{$T\left({ }^{\circ} \mathrm{C}\right)$} & \multirow[b]{2}{*}{$t(\mathrm{~h})$} & \multicolumn{4}{|l|}{ Modes* } & \multirow[b]{2}{*}{ Ref. } \\
\hline & & & $\mathrm{A}_{1}(\mathrm{TO})$ & $\mathrm{E}_{1}(\mathrm{TO})$ & $\mathrm{E}_{2}(\mathrm{low})$ & $\mathrm{E}_{2}($ high $)$ & \\
\hline \multicolumn{8}{|c|}{ Synthesis methods } \\
\hline CL & 400 & 2 & 380 & - & 99 & 438 & 63 \\
\hline ET & 900 & 1 & 380 & 407 & 101 & 437 & 64 \\
\hline SG & 550 & 2 & 380 & 414 & - & 440 & 65 \\
\hline SG & 750 & 2 & 380 & - & - & 435 & 66 \\
\hline $\mathrm{CP}$ & 120 & 2 & 380 & 418 & - & 438 & 26 \\
\hline HT & 120 & 72 & 382 & 409 & 102 & 440 & 5 \\
\hline HT & 130 & 24 & 381 & - & - & 438 & 11 \\
\hline $\mathrm{HT}$ & 80 & 20 & 385 & - & - & 439 & 67 \\
\hline HT & 200 & 10 & 383 & - & - & 438 & 16 \\
\hline MH & 130 & 3 & 378 & - & - & 437 & 68 \\
\hline \multicolumn{8}{|c|}{ Bulks } \\
\hline BK & - & - & 379 & 410 & 102 & 437 & 69 \\
\hline BK & - & - & 380 & 407 & 101 & 437 & 70 \\
\hline BK & - & - & 380 & 413 & 101 & 444 & 71 \\
\hline \multicolumn{8}{|c|}{ Theoretical } \\
\hline TR & - & - & 386 & 407 & 98 & 433 & 72 \\
\hline \multirow[t]{3}{*}{ TR } & - & - & 382 & 316 & 126 & 335 & 73 \\
\hline & & & Modes* & & & & \\
\hline & $T\left({ }^{\circ} \mathrm{C}\right)$ & $t(\mathrm{~h})$ & $\mathrm{A}_{1}(\mathrm{TO})$ & $\mathrm{E}_{1}(\mathrm{TO})$ & $\mathrm{E}_{2}(\mathrm{low})$ & $\mathrm{E}_{2}$ (high) & CTAB \\
\hline
\end{tabular}

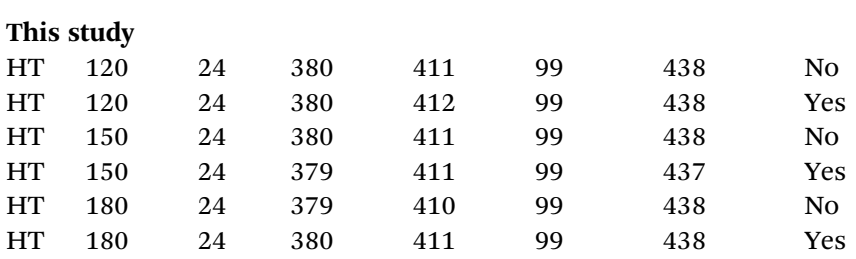

${ }^{a} T=$ temperature; $t=$ time; ${ }^{*}$ Raman modes $=\left(\mathrm{cm}^{-1}\right)$; Ref. $=$ reference; for all the syntheses performed in this study, the reaction time was $24 \mathrm{~h}$; $\mathrm{CTAB}=$ presence of cetyl trimethylammonium bromide; $\mathrm{CL}=$ charged liquid cluster beam; ET $=$ thermal evaporation; $\mathrm{SG}=$ sol-gel; $\mathrm{CP}=$ coprecipitation; $\mathrm{HT}=$ hydrothermal; $\mathrm{MH}=$ hydrothermal microwave; $\mathrm{BK}=$ bulk; $\mathrm{TR}=$ theoretical.

The samples analysed in this study also presented other signals that are not displayed in Fig. 4, such as a wide band of low intensity that appears right above $550 \mathrm{~cm}^{-1}$, which can be attributed to modes $\mathrm{A}_{1}(\mathrm{LO})$ and $\mathrm{E}_{1}(\mathrm{LO})$. The appearance of bands $A_{1}(L O)$ and $E_{1}(L O)$ in the Raman spectra of $\mathrm{ZnO}$ is caused by the formation of structural faults (oxygen and interstitial zinc vacancies), where mode $\mathrm{E}_{1}(\mathrm{LO})$ is more strongly affected by these effects. ${ }^{75}$ The wide band, which also appeared in the Raman spectra with peaks approaching 1100 and $1150 \mathrm{~cm}^{-1}$, corresponds to $2 \mathrm{LO}$ (mode $\left.\mathrm{A}_{1}\right){ }^{5}$ Zhao et $a .^{76}$ reported the possibility of locating a peak at approximately $1350 \mathrm{~cm}^{-1}$, which would indicate three phonons from the Raman scattering processes, $\mathrm{A}_{1}(\mathrm{TO})+\mathrm{A}_{1}(\mathrm{LO})+\mathrm{E}_{2} \mathrm{H}$; however, these peaks do not appear in the Raman spectra of this study.

The information in Table 3 indicates consonance between the Raman modes identified and attributed in this study and 
other studies published in the literature, although there is a slight displacement in the relative position of some peaks. The small changes observed in the characteristic positions of the Raman modes listed in Table 3 can be associated with the degree of crystallinity, grain size distribution and average crystal size, ionic interaction force, degree of structural order and disorder in the crystal lattice, and the presence of structural defects (oxygen vacancy, distortions and/or tensions in the structure). These alterations are confirmed by the PL spectra. The visible band in the PL spectrum only appears in the presence of defects such as Vo of $\mathrm{O}_{2}$ and interstitial $\mathrm{O}_{\mathrm{i}}$, among others. ${ }^{77,78}$ Special attention is given to the efficiency of the hydrothermal method used in this study, as the main characteristic Raman modes for the ZnO wurtzite phase were observed as well as peaks that were not exhibited in other studies in the literature, where less energetic and drastic reaction conditions were applied.

IR spectroscopy is a useful and powerful technique adopted for the analysis, confirmation and elucidation of structures of compounds and to identify the functional groups present in the compounds, ${ }^{79}$ complementing the information obtained from Raman spectroscopy. IR analyses using $\mathrm{KBr}$ pellets in transmission mode are displayed in Fig. 5 for the samples hydrothermally processed for $24 \mathrm{~h}$ at $180{ }^{\circ} \mathrm{C}$, with and without CTAB.

The IR spectra displayed absorption bands between 3400 and $2900 \mathrm{~cm}^{-1}$, which refer to $\mathrm{O}-\mathrm{H}$ and $\mathrm{C}-\mathrm{H}$ vibrations, respectively, where the $\mathrm{O}-\mathrm{H}$ absorption most likely originates from the atmospheric mixture where the analyses are performed, which adsorbs on the surface of the samples and on the KBr pellets. ${ }^{80}$ The modes close to 1400 and $1600 \mathrm{~cm}^{-1}$ represent $\mathrm{C}=\mathrm{O}$ asymmetrical and symmetrical stretching, respectively, and may be associated with the residue from the starting material, $\mathrm{Zn}\left(\mathrm{CH}_{3} \mathrm{COO}\right)_{2} \cdot 2 \mathrm{H}_{2} \mathrm{O}$, still present in the final product. ${ }^{81}$ Nevertheless, emphasis is given to the superposition of bands at approximately $500 \mathrm{~cm}^{-1}$, referent to the $\mathrm{Zn}-\mathrm{O}$ stretching frequency, which is present in all the samples

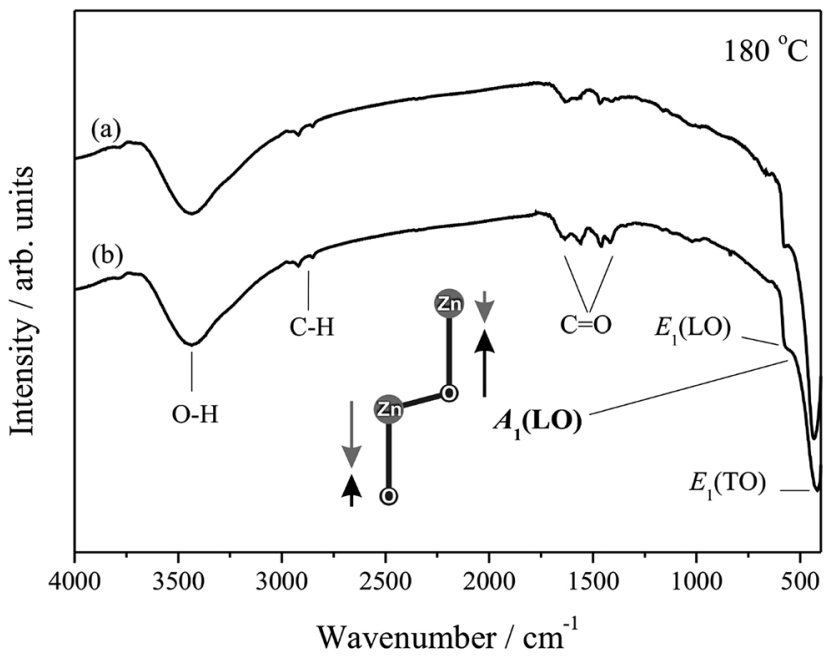

Fig. 5 Infrared spectra of samples of $\mathrm{ZnO}$ hydrothermally processed for $24 \mathrm{~h}$ at $180^{\circ} \mathrm{C}$ in the absence (a) and presence (b) CTAB. The $A_{1}$ mode(LO) is shown. analysed by IR and is indicative of the high orientation of the $\mathrm{ZnO}$ wurtzite crystal structure. ${ }^{79}$

The superposed bands located at approximately 420, 580 and $590 \mathrm{~cm}^{-1}$ are attributed to modes $\mathrm{E}_{1}(\mathrm{TO}), \mathrm{A}_{1}(\mathrm{LO})$ and $\mathrm{E}_{1}(\mathrm{LO})$, respectively. ${ }^{82}$ Another characteristic band of the $\mathrm{ZnO}$ wurtzite phase should appear at approximately $380 \mathrm{~cm}^{-1}$, referent to mode $\mathrm{A}_{1}$ (TO); however, because of the limitations of the equipment used for the analyses, measurements below $400 \mathrm{~cm}^{-1}$ could not be performed using $\mathrm{KBr}$ pellets in transmission mode.

\subsection{FE-SEM analyses}

The FE-SEM micrographs presented in Fig. 6(a-f) show the morphology of the ZnO microcrystals prepared at 120, 150 and $180{ }^{\circ} \mathrm{C}$ for $24 \mathrm{~h}$, with and without CTAB. The FE-SEM micrographs demonstrate the predominance of $\mathrm{ZnO}$ microcrystals in the form of hexagonal columns in the absence of CTAB and of double hexagonal columns in the presence of CTAB. Similarly, for the samples synthesised at $180^{\circ} \mathrm{C}$ in the presence or absence of CTAB, the shape of the hexagonal columns is different, as the (001) crystal face exhibits a smaller diameter in relation to face (001). Hence, these $\mathrm{ZnO}$ samples synthesised at $180{ }^{\circ} \mathrm{C}$ were analysed using energy dispersive spectroscopy (EDS) to evaluate the chemical composition. The insert in Fig. 6(e and f) shows a typical EDS spectrum of ZnO crystals. ${ }^{16}$ The result confirms that each crystal is composed of $\mathrm{Zn}$ and $\mathrm{O}$ (the $\mathrm{Au}$ and $\mathrm{C}$ peaks originate from elements in the sample holder).

Based on the FE-SEM images, the crystal size distribution was estimated considering the average of 100 particles $(N=100)$ for every one of the synthesised samples in this study, as illustrated in Fig. 7. The size estimations were performed considering each particle individually, including those that exhibited the form of a double hexagonal column, as observed for the samples processed in the presence of CTAB.

The ZnO microcrystals exhibit a polydisperse particle size distribution. Fig. 7 shows the tendency of reduction in the average size of individual microcrystals with an increase in temperature from 95 to $97 \%$ (without CTAB) and from 74 to $77 \%$ (with $\mathrm{CTAB}$ ). The reduction of the average size is more evident in the samples prepared at $180{ }^{\circ} \mathrm{C}$. Additionally, the presence of $\mathrm{CTAB}$ affects the growth of the $\mathrm{ZnO}$ microcrystals, where, for the same processing conditions, the average size of individual microcrystals was between 46 and 93\% larger.

Recently, different ZnO morphologies, such as rods, flowers, spheres, disks, and hexagonal columns, have been synthesised using different methods, as displayed in Table 4. . $^{2,5,11,16,27,46,68,83-96}$ Various methods can be used to obtain $\mathrm{ZnO}$ crystal structures; however, the hydrothermal approach from aqueous solutions offers advantages, such as the low processing temperature and the use of simple material, its appropriateness for large-scale application and economic advantages. ${ }^{83}$

\subsection{Growth process}

Based on the experimental results and orientation type of crystal growth, the possible growth mechanism of $\mathrm{ZnO}$ crystals of hexagonal column form belongs to the Ostwald ripening mechanism and is also involved in the selective adsorption of 

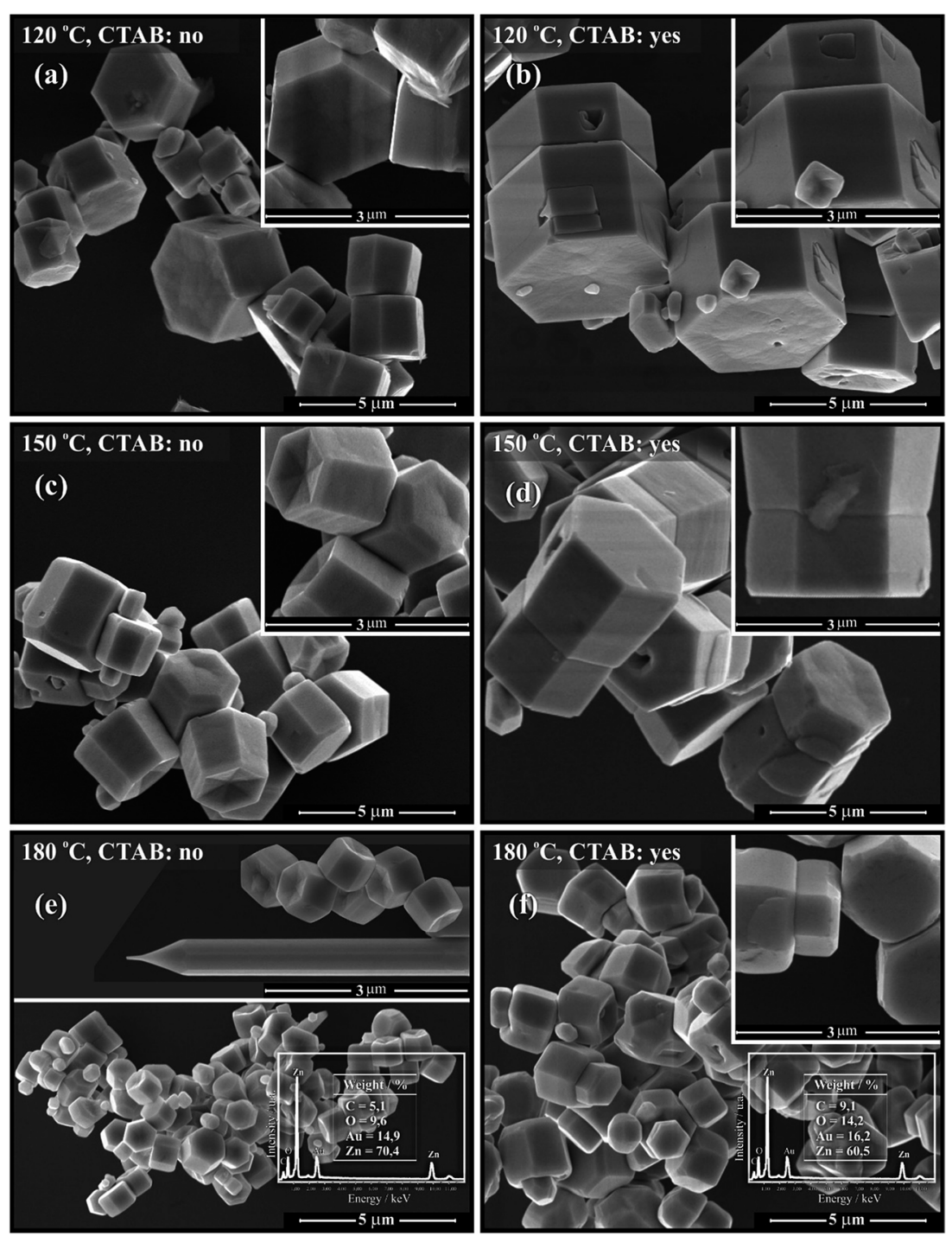

Fig. 6 FE-SEM micrographs of $\mathrm{ZnO}$ microstructures obtained by hydrothermal processing at $120{ }^{\circ} \mathrm{C}(\mathrm{a})$ without and (b) with the assistance of $\mathrm{CTAB}$; at $150^{\circ} \mathrm{C}$ (c) without and (d) the assistance of CTAB; and at $180^{\circ} \mathrm{C}$ (e) without and (f) with the assistance of CTAB. The energy dispersive spectroscopy (EDS) elemental analysis is displayed as an insertion for the samples obtained at $180{ }^{\circ} \mathrm{C}$ (e and f).

zincate growth units $\left[\mathrm{Zn}(\mathrm{OH})_{4}\right]^{2-}$ along the polar axis $[001]$ of the $\mathrm{ZnO}$ crystal structure. ${ }^{92}$ This process is considered simple and innovative. ${ }^{87}$

The crystal formation process includes nucleation and growth. Initially, because of the decomposition of ZAD at high temperature, the concentrations of $\mathrm{Zn}^{2+}$ and $\mathrm{OH}^{-}$increase correspondingly. When the supersaturation degree exceeds the critical value, the $\mathrm{ZnO}$ nuclei start to form. The mechanism suggested in this study for the formation of $\mathrm{ZnO}$ microcrystals hydrothermally processed at 120,150 and $180{ }^{\circ} \mathrm{C}$, with and without the assistance of CTAB, is proposed in Fig. 8.

The $\mathrm{ZnO}$ synthesis without surfactant addition is classified as "organic-free". ${ }^{88}$ Under hydrothermal conditions, the possible involved reactions are

$$
\begin{gathered}
\mathrm{Zn}^{2+}+4 \mathrm{OH}^{-} \rightarrow\left[\mathrm{Zn}(\mathrm{OH})_{4}\right]^{2-} \\
{\left[\mathrm{Zn}(\mathrm{OH})_{4}\right]^{2-} \leftrightarrow \mathrm{Zn}(\mathrm{OH})_{2}+2 \mathrm{OH}^{-}}
\end{gathered}
$$

$$
\begin{gathered}
\mathrm{Zn}(\mathrm{OH})_{2} \leftrightarrow \mathrm{ZnO}+\mathrm{H}_{2} \mathrm{O} \\
{\left[\mathrm{Zn}(\mathrm{OH})_{4}\right]^{2-} \leftrightarrow \mathrm{ZnO}+2 \mathrm{H}_{2} \mathrm{O}+2 \mathrm{OH}^{-}}
\end{gathered}
$$

The experimental results revealed that the hydrothermal conditions, particularly the basic concentration of the solution and the temperature, affect the morphology and size of the crystallite. The modification of the physico-chemical conditions during the growth process is considered to essentially alter the solution structure, i.e., the structural form of the growth units and the nature of the growth interfaces. Therefore, an approach could be performed in relation to the incorporation of growth units in the different faces and the nature of the crystal growth interfaces under the effect of the addition of $\mathrm{OH}^{-}$ions to interpret the formation mechanism of the observed morphology.

The ZAD precursor undergoes hydrolysis, which induces the (3) formation of $\mathrm{Zn}(\mathrm{OH})_{2}$. The $\mathrm{Zn}(\mathrm{OH})_{2}$ is a hydroxide of 

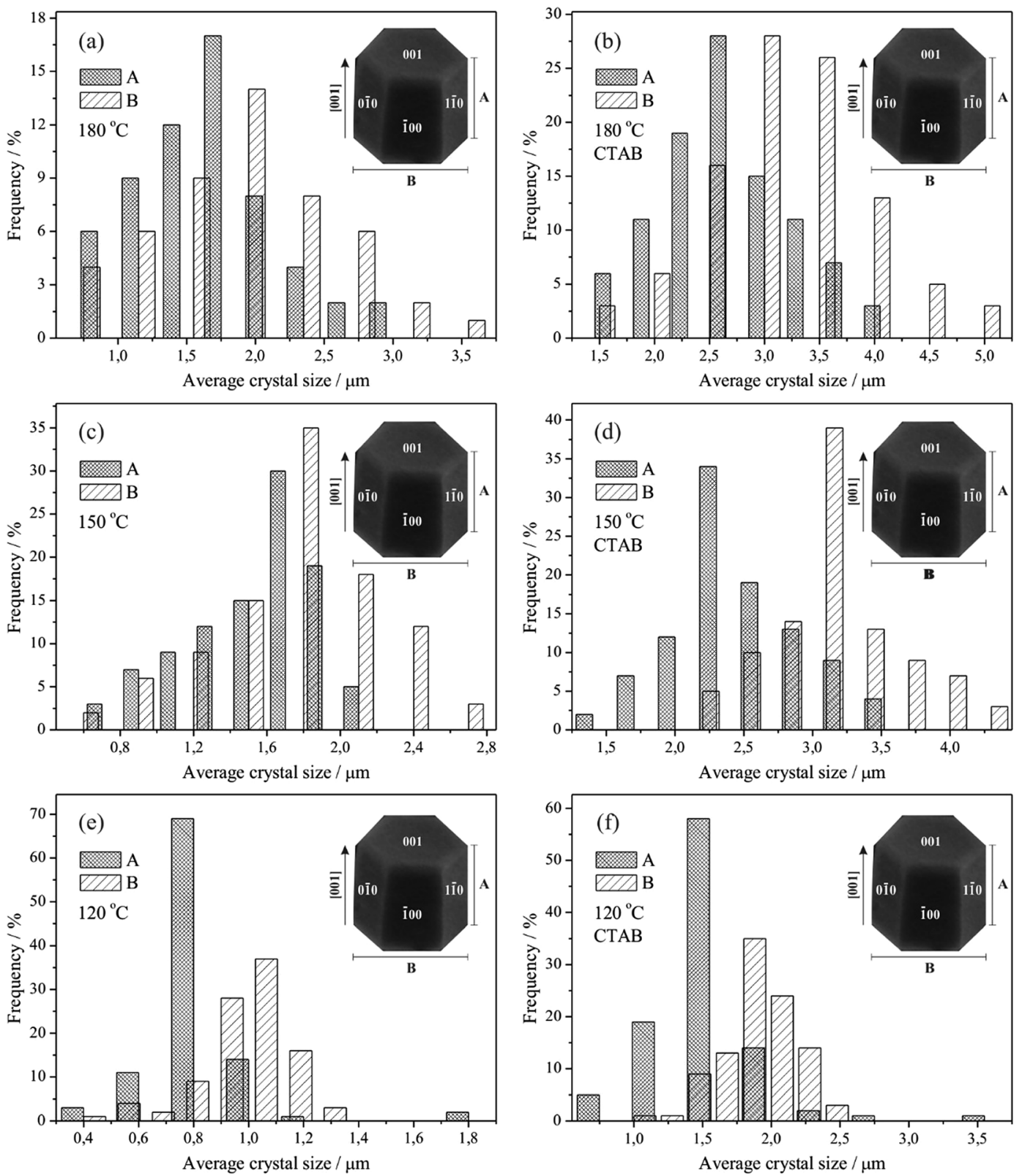

Fig. 7 Size distribution of $\mathrm{ZnO}$ microcrystals obtained by hydrothermal processing with $N=100$ at $120^{\circ} \mathrm{C}$ (a) in the absence and (b) presence of $\mathrm{CTAB}$; at $150{ }^{\circ} \mathrm{C}$ (c) in the absence and (d) presence of $\mathrm{CTAB}$; and at $180{ }^{\circ} \mathrm{C}$ (e) in the absence and (f) presence of $\mathrm{CTAB}$.

amphoteric character, and its solubility is particularly related to the alkalinity of the solution and the temperature. ${ }^{97}$ Thus, the solubility increases with the increase of temperature. $\mathrm{Zn}(\mathrm{OH})_{2}$ is dissolved in the solution to form the zincate complex $\left[\mathrm{Zn}(\mathrm{OH})_{4}\right]^{2-}$ in the basic solution; these complex groups are called crystal growth units, where these growth units dehydrate when they are incorporated in the crystal. ${ }^{46}$ Furthermore, the complexes (growth units) exhibit polaron behaviour because of the tetrahedron structure characteristic, i.e., the asymmetrical position of the $\mathrm{Zn}$ atom. The vertex of the tetrahedral exhibits a negative charge, whereas the base exhibits a positive charge and, similarly, the structured units, i.e., the $\mathrm{Zn}-\mathrm{O}_{4}$ crystal tetrahedron. In turn, the amount of $\mathrm{OH}^{-}$in the solution has a significant effect on the nature of the growth interface, particularly on the two polar faces, and therefore on the rate of incorporation in these faces.

The detailed analyses of the incorporation of $\left[\mathrm{Zn}(\mathrm{OH})_{4}\right]^{2-}$ (zincate) growth units on the positive and negative faces are described next. In a solution with high $\mathrm{pH}$ under hydrothermal conditions, the starting material is completely dissolved, and all that is dissolved in the form of $\mathrm{Zn}(\mathrm{OH})_{2}$ is complexed with $\mathrm{OH}^{-}$ to form zincate $\left[\mathrm{Zn}(\mathrm{OH})_{4}\right]^{2-}$, which exhibits a negative charge. In turn, reminiscent $\mathrm{OH}^{-}$remains in the solution, which can affect the growth interface. Once the positive crystal face (001) is occupied by $\mathrm{Zn}$ atoms, the $\mathrm{OH}^{-}$ions in solution can be adsorbed on the face and modify the nature of the interface. ${ }^{\mathbf{1 6}}$ 
Table 4 Morphology and size of ZnO micro- and nanocrystal structures from studies reported in the literature, obtained using different synthesis methods $^{a}$

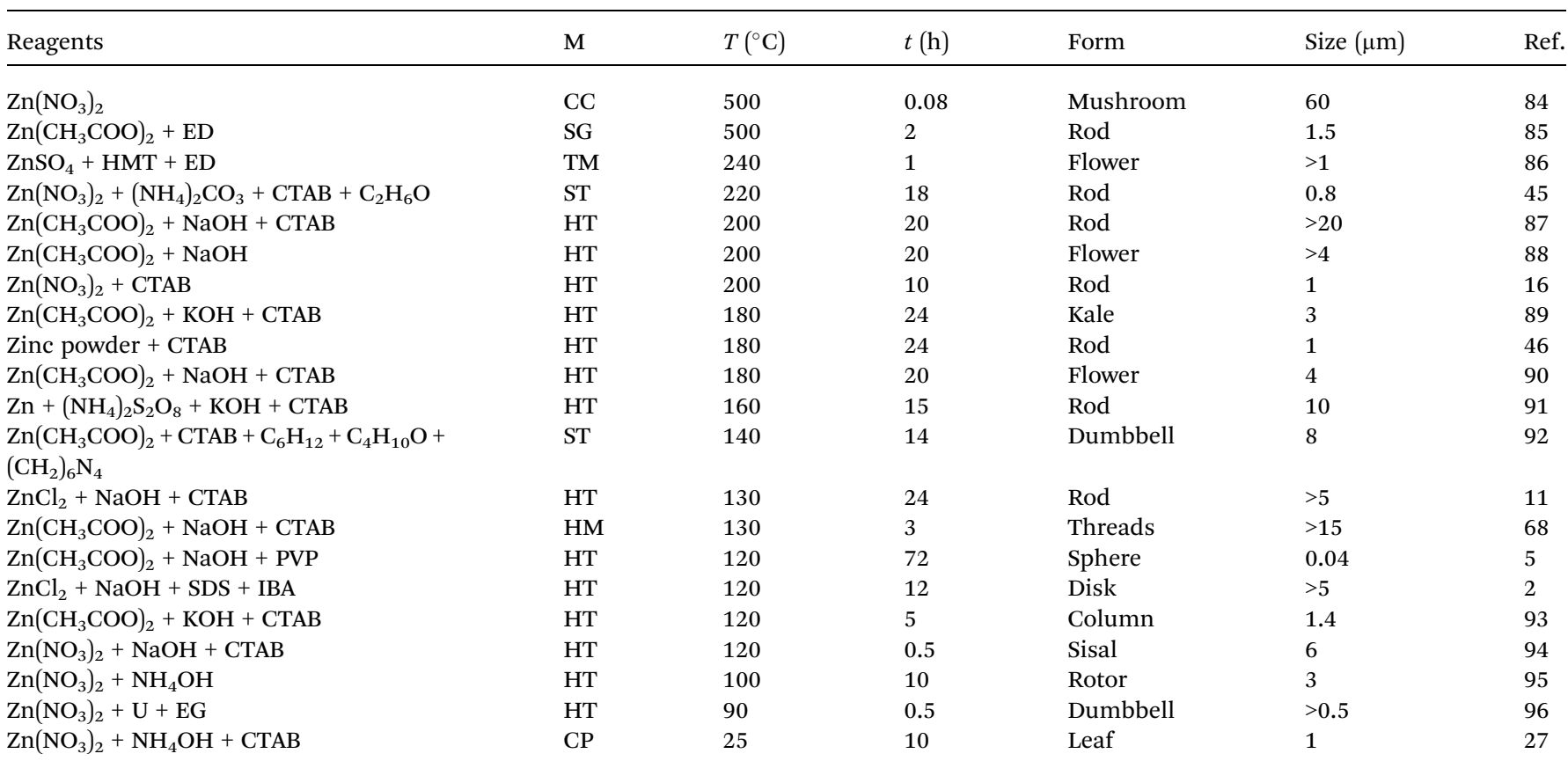

${ }^{a} \mathrm{M}=$ method; $T=$ temperature; $t=$ time; size = size; Ref. = reference; $\mathrm{CC}=$ calcination; $\mathrm{SG}=$ sol-gel; $\mathrm{TM}=$ thermolysis; $\mathrm{ST}=$ solvothermal; $\mathrm{HT}=$ hydrothermal; $\mathrm{HM}=$ hydrothermal microwave; $\mathrm{CP}=$ coprecipitation; $\mathrm{Zn}\left(\mathrm{NO}_{3}\right)_{2}=$ zinc nitrate; $\mathrm{Zn}\left(\mathrm{CH}_{3} \mathrm{COO}\right)_{2}=$ zinc acetate; $\mathrm{ED}=$ ethylenediamine; $\mathrm{HMT}=$ hexamethylenetetramine; $\left(\mathrm{NH}_{4}\right)_{2} \mathrm{CO}_{3}=$ ammonium carbonate; $\mathrm{CTAB}=$ cetyl trimethylammonium bromide; $\mathrm{C}_{2} \mathrm{H}_{6} \mathrm{O}=\mathrm{ethanol} ; \mathrm{NaOH}=$ sodium hydroxide; $\mathrm{KOH}=$ potassium hydroxide; $\mathrm{Zn}=$ zinc powder; $\left(\mathrm{NH}_{4}\right)_{2} \mathrm{~S}_{2} \mathrm{O}_{8}=$ ammonium peroxodisulphate; $\mathrm{C}_{6} \mathrm{H}_{12}=$ cyclohexane; $\mathrm{C}_{4} \mathrm{H}_{10} \mathrm{O}$ $=n$-butanol; $\left(\mathrm{CH}_{2}\right)_{6} \mathrm{~N}_{4}=$ methenamine; $\mathrm{ZnCl}_{2}=$ zinc chloride; PVP = polyvinylpyrrolidone; SDS = sodium dodecyl sulphate; IBA = isobutanol; $\mathrm{NH}_{4} \mathrm{OH}=$ ammonium hydroxide; $\mathrm{U}=$ urea; $\mathrm{EG}=$ ethylene glycol.

Therefore, it becomes more difficult to incorporate the growth units on the positive and negative faces. The polar faces grow slowly and are developed with larger size, resulting into a regular morphology, such as hexagonal columns. According to observations, the temperature accelerates the reaction process, and at $180{ }^{\circ} \mathrm{C}$, the (001) face tends to be smaller in the final stage.

Wang et $a .^{46}$ reported that $\mathrm{Zn}(\mathrm{OH})_{2}$ not only contributes to the nucleation of $\mathrm{ZnO}$ as previously mentioned but also transforms into zincate $\left[\mathrm{Zn}(\mathrm{OH})_{4}\right]^{2-}$, increasing the growth rate of $\mathrm{ZnO}$. Furthermore, in the reaction at high temperature, active sites can be generated around the circumference of the $\mathrm{ZnO}$ nucleus, causing the $\mathrm{ZnO}$ to grow preferentially in the active known to be a polar crystal whose positive plane is rich in $\mathrm{Zn}$ and whose negative plane is rich in $\mathrm{O}$. In the hydrothermal process, the growth unit $\left[\mathrm{Zn}(\mathrm{OH})_{4}\right]^{2-}$ leads to different growth rates of the planes: $V(001)>V(1 \overline{1} 0)>V(\overline{1} 00)>V(0 \overline{1} 0)>V(00 \overline{1}) \cdot{ }^{88}$ Generally, a faster growth rate corresponds to faster disappearance of the place. Therefore, the (001) plane of $\mathrm{ZnO}$, with a fast growth rate associated with the high temperature, tends to disappear at the end of the hydrothermal process, which generates the point at the end of the $c$ axis. In turn, the (001) plane, the slower growth rate plane, is maintained during the hydrothermal process. Hence, at $180^{\circ} \mathrm{C}$, at higher temperature, the form of the hexagonal columns can be altered, with a thinner (001) crystal face.
A possible growth mechanism for the $\mathrm{ZnO}$ microstructures at different temperatures and in the presence of CTAB is described next. The following chemical reactions are involved in the process:

$$
\begin{gathered}
\mathrm{Zn}^{2+}+2 \mathrm{OH}^{-} \rightarrow \mathrm{Zn}(\mathrm{OH})_{2} \\
\mathrm{Zn}(\mathrm{OH})_{2} \leftrightarrow \mathrm{ZnO}+\mathrm{H}_{2} \mathrm{O} \\
\mathrm{Zn}(\mathrm{OH})_{2}+2 \mathrm{OH}^{-} \leftrightarrow\left[\mathrm{Zn}(\mathrm{OH})_{4}\right]^{2-} \\
\mathrm{CTAB} \leftrightarrow \mathrm{CTA}^{+}+\mathrm{Br}^{-} \\
{\left[\mathrm{Zn}(\mathrm{OH})_{4}\right]^{2-}+\mathrm{CTA}^{+} \leftrightarrow \mathrm{CTA}^{+}-\left[\mathrm{Zn}(\mathrm{OH})_{4}\right]^{2-}} \\
\mathrm{CTA}^{+}-\left[\mathrm{Zn}(\mathrm{OH})_{4}\right]^{2-} \leftrightarrow \mathrm{ZnO}+\mathrm{H}_{2} \mathrm{O}+\mathrm{CTA}^{+}
\end{gathered}
$$

The presence of CTAB, which is a cationic surfactant, reduces the surface tension of the solution, which decreases the energy necessary to form a new phase, and therefore, the $\mathrm{ZnO}$ crystals can be formed at a temperature lower than supersaturation. As previously mentioned, the $\mathrm{ZnO}$ crystal growth unit is zincate $\left[\mathrm{Zn}(\mathrm{OH})_{4}\right]^{2-}$; therefore, in aqueous solutions, the $\left[\mathrm{Zn}(\mathrm{OH})_{4}\right]^{2-}$ anions and $\mathrm{CTA}^{+}$cations in solution during the hydrothermal process interact electrostatically to form complexing agents that are adsorbed on the surface of $\mathrm{ZnO}$ nuclei. Because of this adsorption, the surface energy of the $\mathrm{ZnO}$ 

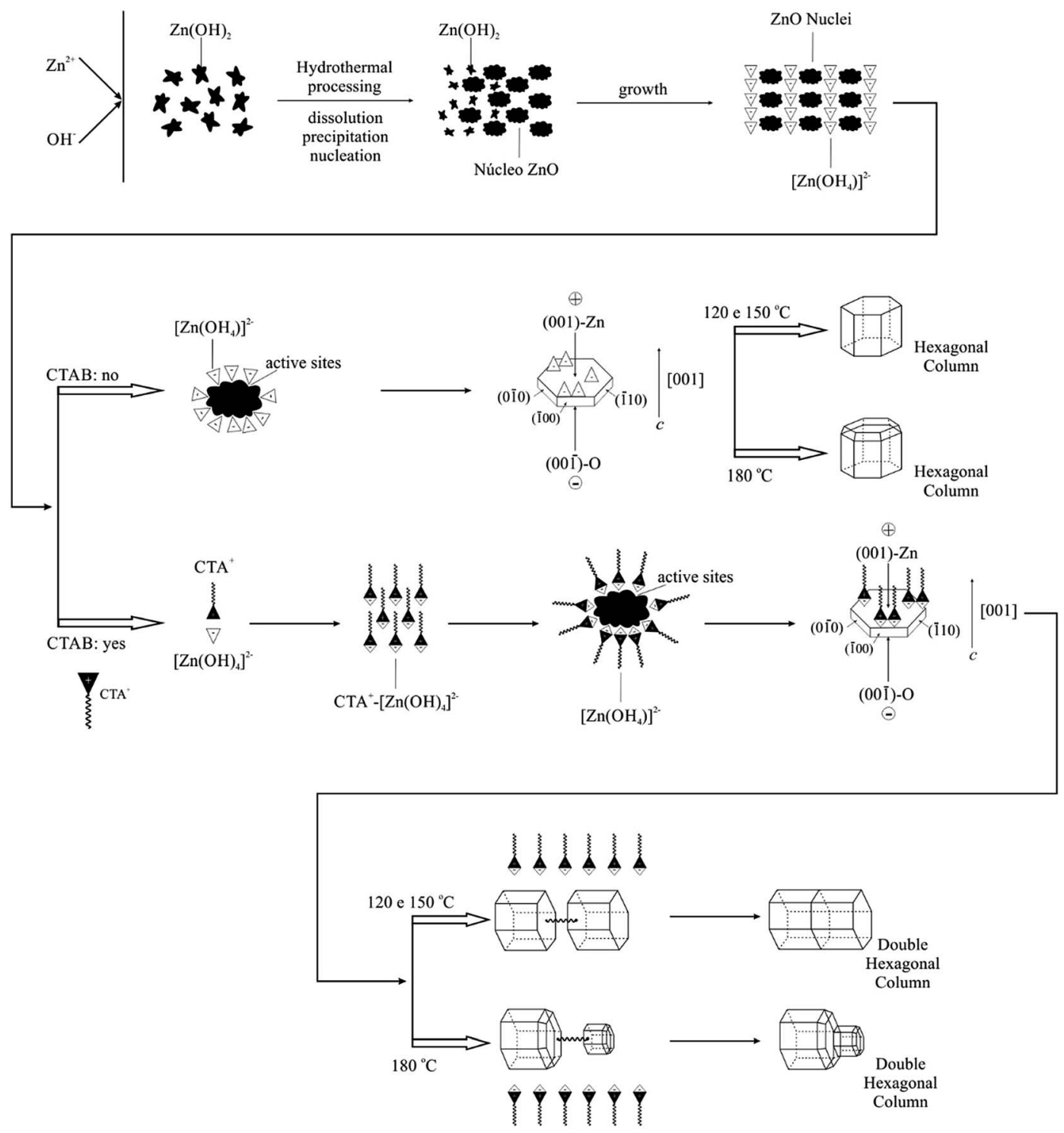

Fig. 8 Schematic diagram of the mechanism proposed for the growth of ZnO microstructures in the form of simple and double hexagonal columns, obtained by hydrothermal processing at 120,150 and $180^{\circ} \mathrm{C}$, with and without the assistance of CTAB.

nucleus decreases, resulting in active sites generated on the surface. Additionally, the temperature acts directly on the permanent dipole of water and increases the kinetic behaviour of crystallisation by one or two orders of magnitude. ${ }^{68}$

During the hydrothermal process, the CTAB acts as a transportation mode for the $\left[\mathrm{Zn}(\mathrm{OH})_{4}\right]^{2-}$ growth units. According to the internal structure and crystal growth cell, the $\mathrm{ZnO}$ exhibits a preferential growth behaviour along the $c$ axis. These growth units are combined among themselves and decompose into $\mathrm{ZnO}$ nuclei simultaneously from the tetrahedral face of $\mathrm{Zn}-\mathrm{O}_{4}$ and auto-organise to form microstructures in the form of hexagonal columns. The number of $\left[\mathrm{Zn}(\mathrm{OH})_{4}\right]^{2-}$ growth units increases at $180{ }^{\circ} \mathrm{C}$, most likely because the high temperature accelerates the microcrystal growth reaction; consequently, the number of $\mathrm{ZnO}$ nuclei also decreases, reducing the surface potential. ${ }^{89}$
For hydrothermal processing with the assistance of CTAB, the same previously mentioned comments are valid. The $\mathrm{ZnO}$ microcrystal formation process under hydrothermal conditions can be represented as follows: the ZAD precursor undergoes hydrolysis, which induces the formation of $\mathrm{Zn}(\mathrm{OH})_{2}$. During the hydrothermal process, some of the $\mathrm{Zn}(\mathrm{OH})_{2}$ colloids are dissolved into $\mathrm{Zn}^{2+}$ and $\mathrm{OH}^{-}$. When the concentrations of $\mathrm{Zn}^{2+}$ and $\mathrm{OH}^{-}$reach the $\mathrm{ZnO}$ supersaturation degree, the $\mathrm{ZnO}$ nucleus is formed. The $\left[\mathrm{Zn}(\mathrm{OH})_{4}\right]^{2-}$ growth units exhibit a tetrahedral geometry. ${ }^{\text {98-100 }}$

The CTAB is completely ionised in water. The $\mathrm{CTA}^{+}$is positively charged with a tetrahedral head and a long hydrophobic tail. The resulting cation is also a tetrahedron with a long hydrophobic tail. Therefore, ion pairs can be formed between $\left[\mathrm{Zn}(\mathrm{OH})_{4}\right]^{2-}$ and $\mathrm{CTA}^{+}$because of the electrostatic interaction. The critical micelle concentration (CMC) of the pure CTAB in 
aqueous solution at $25{ }^{\circ} \mathrm{C}$ is $0.0009 \mathrm{M}^{45}$ and the CTAB concentration used in this study is approximately $0.1 \mathrm{M}$, and, in this case, the CTAB aggregation in aqueous solution forms spherical micelles. Only the micelles in aqueous solutions are in dynamic equilibrium; the $\left[\mathrm{Zn}(\mathrm{OH})_{4}\right]^{2-}$ and $\mathrm{CTA}^{+}$ion pairs are constantly adsorbed and separated at the surface of the formed micelle. The complementarity between $\left[\mathrm{Zn}(\mathrm{OH})_{4}\right]^{2-}$ and $\mathrm{CTA}^{+}$ enables the surfactant to act as an ionic carrier. It should also be highlighted that the CMC of CTAB increases as the temperature increases. $^{45}$

According to Sun et al., ${ }^{46}$ in the presence of CTAB, a fluctuating film is formed. When the surfactant agent molecules exit, zincate is transported in the form of an ionic pair, such that the boundary layer becomes finer, which facilitates the interaction process of the active sites. In the crystallisation process, the surfactant molecules can act as growth controllers as well as agglomeration inhibitors by forming a film on the newly formed $\mathrm{ZnO}$ crystal.

The adsorption of growth units at the crystal surface strongly affects the rate of formation and orientation of crystals. When a $\mathrm{ZnO}$ crystal grows, a surfactant film can be formed at the interface between the solution and $\mathrm{ZnO}$ crystal, reducing the interface energy. The floating film and surfactant molecules that transport the growth units will release them on the surface of the $\mathrm{ZnO}$ crystal. As the CTAB favours the formation of a film where the molecules tend to be perpendicular to the adsorbed surface, the growth units tend to fit in the face at the growth interface. Thus, this type of fit and the dehydration result in three $\mathrm{Zn}-\mathrm{O}-\mathrm{Zn}$ bonds, making this fit mode predominant and competing with others as the fitting in the vertex and edge. The ZnO crystal grows preferentially along the $c$ axis ([001] direction) due to this fitting type in the (001) crystal face and the repeated dehydration steps. According to the previously mentioned process, it is supposed that CTAB not only accelerates the reaction as a growth unit transporter but also leads to the oriented growth of the $\mathrm{ZnO}$ microcrystals. ${ }^{27}$

Liu et $a .^{92}$ reported that in the initial hydrothermal process, the growth unit of negative nature $\left[\mathrm{Zn}(\mathrm{OH})_{4}\right]^{2-}$ leads to different growth rates of $\mathrm{ZnO}$ particle planes and lamellas, which will be easily developed because of the Ostwald ripening process. ${ }^{96}$ As the reaction occurs, initially, the large surface areas of the lamellar crystals are dissolved and re-precipitate to form larger crystals of low energy and hexagonal morphology of double hexagonal columns. Recent studies with similar morphologies identified defects at the basal plane with inversion domain boundaries (IDBs). When the boundary inversion is formed in the $\mathrm{ZnO}$, the head-to-head configuration appears predominantly along the polar axis $c$, i.e., planes with oxygen terminations oriented towards the other plane interface (001). In fact, the formation of double microstructures involves structural and energetic factors; however, the driving force behind the formation of this type of morphology remains under discussion in the literature. ${ }^{92}$ Gao et $a .^{86}$ believe that the formation of double crystals in $\mathrm{ZnO}$ samples prepared under hydrothermal conditions is linked to the presence of organic additives, which provide models for the nucleation and orientation of $\mathrm{ZnO}$ crystal growth and, consequently, results in units in the form of fuse (axis), with half of the interface. Wang et al. ${ }^{101}$ reported the synthesis of $\mathrm{ZnO}$ in the form of dumbbells (double crystal) by the hydrothermal process using $\mathrm{K}^{+}$as a mineraliser. In this hydrothermally process, $\mathrm{K}^{+}$can act as a bond unit between tetrahedral $\left[\mathrm{ZnO}_{4}\right]^{6-}$ and leads to the initial formation of a double crystal nucleus, with head-to-head or tetrahedral tail-to-tail orientation depending on the conditions of preparation. In turn, in the present study, the majority of $\mathrm{Zn}^{2+}$ ions were precipitated as $\mathrm{Zn}(\mathrm{OH})_{2}$. Under hydrothermal conditions, the $\mathrm{Zn}(\mathrm{OH})_{2}$ precipitates were transformed into $\left[\mathrm{Zn}(\mathrm{OH})_{4}\right]^{2-}$ growth units. In the presence of CTAB, the growth units can be bonded by CTAB in the (001) composition plane to form the crystal nuclei in the form of double hexagonal columns. To reduce the surface energy, the individual crystallite growth in the double crystal occurs along the $c$ polar axis by incorporating units in the (001) growth interfaces, and therefore, $\mathrm{ZnO}$ crystals in the form of double hexagonal columns are ultimately formed.

\subsection{Diffuse reflectance}

The direct optical band gap energy $\left(E_{\mathrm{g}}\right)$ was calculated using the method proposed by Kubelka and Munk. ${ }^{\mathbf{1 0 2}}$ This methodology is based on the transformation of the diffuse reflectance measurements $(R)$ to estimate the optical $E_{\mathrm{g}}$ values with good precision. The equation by Kubelka-Munk (12) for any wavelength is described as

$$
F\left(R_{\infty}\right)=\frac{\left(1-R_{\infty}\right)^{2}}{2 R_{\infty}}=\frac{k}{s}
$$

The analyses were performed using magnesium oxide (MgO) as the reference standard, where $R_{\infty}=R_{\text {sample }} / R_{\mathrm{MgO}}\left(R_{\infty}\right.$ is the reflectance when the sample has infinite thickness), $k$ is the coefficient of molar absorption and $s$ is the scattering coefficient. In a parabolic band structure, the optical $E_{\mathrm{g}}$ and absorption coefficient of semiconducting oxides can be calculated using eqn (13):

$$
\alpha h \nu=C_{1}\left(h \nu-E_{\mathrm{g}}\right)^{n}
$$

where $\alpha$ is the coefficient of linear absorption of the material, $h \nu$ is the photon energy, $C_{1}$ is the proportionality constant, $E_{\mathrm{g}}$ is the optical band gap and $n$ is the constant associated with different types of electronic transitions $(n=0.5$, direct allowed; $n=2$, indirect allowed; $n=1.5$, indirect forbidden; and $n=3$, direct forbidden). According to the literature, wurtzite $\mathrm{ZnO}$ exhibits an optical absorption spectrum ruled by direct electronic transitions. ${ }^{5}$ In this phenomenon, after the electronic absorption process, the electrons located in the maximum energy states in the valence shell return to the minimum energy states in the conduction band under the same point of the Brillouin zone. Based on this information, the $E_{\mathrm{g}}$ values of $\mathrm{ZnO}$ were calculated using $n=0.5$ in eqn (13). Finally, using the remission function and the $k=2 \alpha$ term, the modified Kubelka-Munk equation was obtained, as shown in eqn (14):

$$
\left[F\left(R_{\infty}\right) h \nu\right]^{2}=C_{2}\left(h \nu-E_{\mathrm{g}}\right)
$$

Consequently, after determining the value of $F\left(R_{\infty}\right)$ from eqn (14) and plotting a graph of $\left[F\left(R_{\infty}\right) h \nu\right]^{2}$ versus $h \nu$ and $C_{2}$, the $E_{\mathrm{g}}$ of 
the $\mathrm{ZnO}$ crystals was determined by extrapolation of the linear region of the curves, making $[F(R) h \nu]^{2}=0$, as shown in Fig. 9.

Fig. 9 shows that the optical $E_{\mathrm{g}}$ values of $\mathrm{ZnO}$ crystals hydrothermally synthesised without $\mathrm{CTAB}$ varied from 3.15 to $3.20 \mathrm{eV}$, and those synthesised with CTAB varied from 3.13 to $3.21 \mathrm{eV}$. In this case, it was verified that the optical $E_{\mathrm{g}}$ values increase with decreasing particle size and increasing temperature for the samples synthesised with or without CTAB, which may suggest that $\mathrm{ZnO}$ crystals prepared at 120 and $150{ }^{\circ} \mathrm{C}$ absorb more visible light and that at $180^{\circ} \mathrm{C}$, this absorption is smaller. ${ }^{5}$

Table 5 presents the experimental values of optical $E_{\mathrm{g}}$ for $\mathrm{ZnO}$ crystals reported in the literature, which were obtained using different synthesis and bulk methods. The optical $E_{\mathrm{g}}$ values for the $\mathrm{ZnO}$ crystals (Fig. 9) differ slightly from the values reported in the literature for pure $\mathrm{ZnO}$ crystals. These discrepancies can be attributed to the fact that optical $E_{\mathrm{g}}$ is strongly dependent on the synthesis method, defect levels in the optical band gap, morphology and average crystal size, structural orientation and distortions. ${ }^{103}$ Next, some considerations are made regarding these effects. ${ }^{\mathbf{7 9 , 1 0 3 - 1 1 0}}$

As previously stated, $E_{\mathrm{g}}$ can be affected by various factors, including crystal defects ${ }^{111-113}$ and sizes. ${ }^{114,115}$ Huo and $\mathrm{Hu}^{104}$ demonstrated a linear correlation between the $E_{\mathrm{g}}$ of $\mathrm{ZnO}$ and the size of the crystal nanoparticles, which indicates that the increase of $E_{\mathrm{g}}$ can be attributed to the decrease of the crystal size. It is also known that when the crystal size is very small (nanometric scale), $E_{\mathrm{g}}$ increases as the crystal size
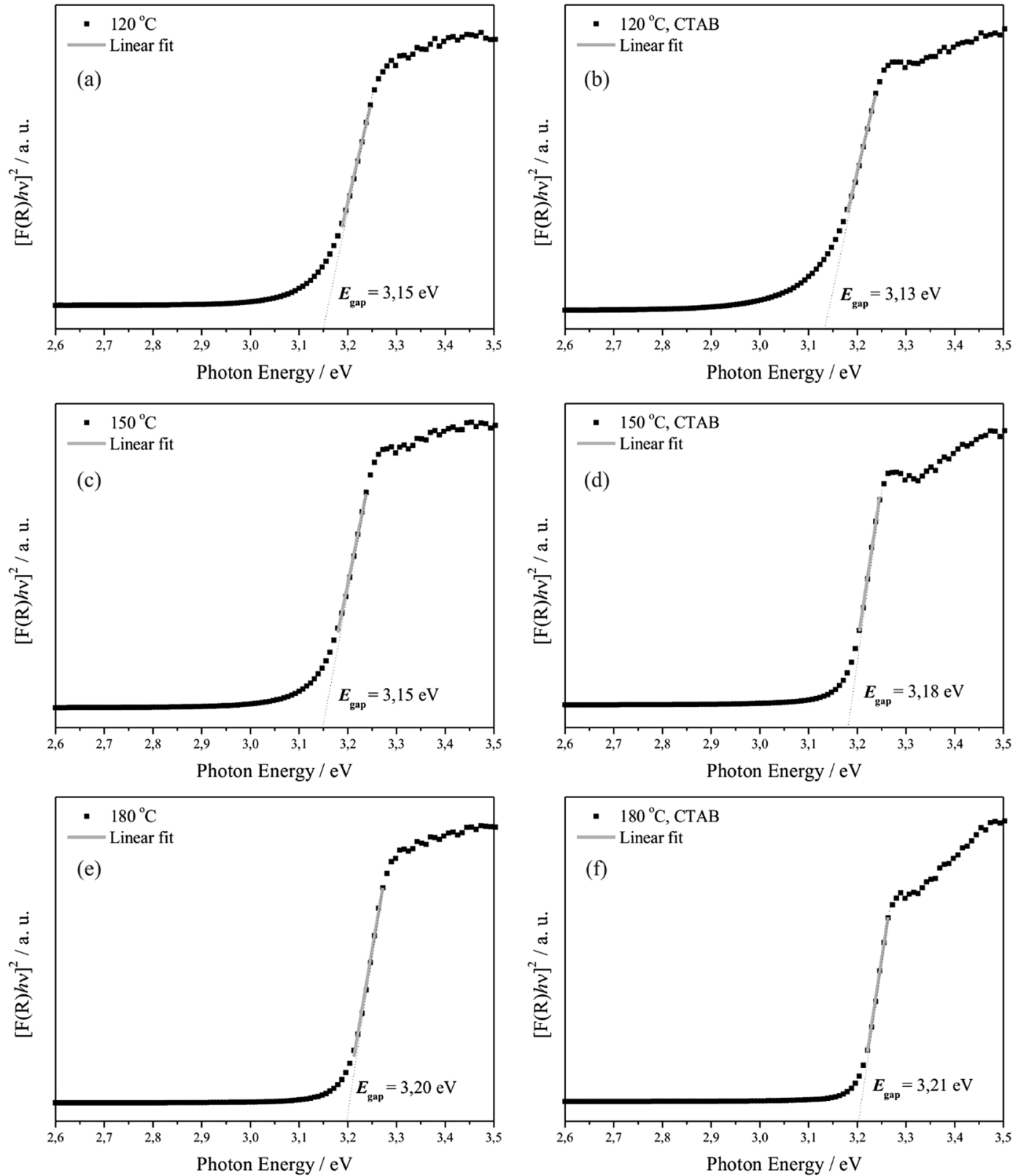

Fig. 9 Kubelka-Munk curves $\left([F(R) h \nu]^{2}\right.$ versus $h \nu$ in eV) of the $\mathrm{ZnO}$ samples hydrothermally processed for $24 \mathrm{~h}$ at $120^{\circ} \mathrm{C}$ (a) without and (b) with the assistance of $C T A B$; at $150{ }^{\circ} \mathrm{C}$ (c) without and (d) with the assistance of CTAB; and at $180{ }^{\circ} \mathrm{C}$ (e) without and (f) with the assistance of $\mathrm{CTAB}$. 
Table 5 Experimental values of the band gap energy $\left(E_{\mathrm{g}}\right)$ of $\mathrm{ZnO}$ crystals reported in the literature obtained using different synthesis and bulk methods ${ }^{a}$

\begin{tabular}{|c|c|c|c|c|}
\hline & $T\left({ }^{\circ} \mathrm{C}\right)$ & $t(\mathrm{~h})$ & $E_{\mathrm{g}}(\mathrm{eV})$ & Ref. \\
\hline \multicolumn{5}{|c|}{ Synthesis methods } \\
\hline $\mathrm{CC}$ & 1000 & 4 & 3.12 & 87 \\
\hline $\mathrm{PC}$ & 700 & 1 & 3.25 & 105 \\
\hline PT & 600 & 1 & 3.17 & 106 \\
\hline GR & 600 & 1 & 3.14 & 103 \\
\hline SG & 400 & 1 & 3.20 & 107 \\
\hline PM & 200 & 2 & 3.26 & 79 \\
\hline HT & 90 & 6 & 3.36 & 108 \\
\hline \multicolumn{5}{|c|}{ Bulks } \\
\hline BK & - & - & 3.35 & 109 \\
\hline $\mathrm{BK}$ & - & - & 3.36 & 110 \\
\hline
\end{tabular}

decreases. ${ }^{116,117}$ However, the dependence of $E_{\mathrm{g}}$ on size has not yet been reported for crystal particles larger than $100 \mathrm{~nm} .{ }^{\mathbf{1 0 4}}$ The results of this study demonstrate that the dependence of $E_{\mathrm{g}}$ in relation to size occurs even at the micrometric scale.

Considering the molecular orbitals, two factors can determine the changes of $E_{\mathrm{g}}$ with the increase of crystal size: the Coulomb interaction displaces $E_{\mathrm{g}}$ to lower values, whereas the quantum location displaces $E_{\mathrm{g}}$ to higher energies. ${ }^{\mathbf{1 0 5 , 1 1 8}}$ Hence, the apparent $E_{\mathrm{g}}$ tends to increase for a small crystal size, where the change in $E_{\mathrm{g}}$ is determined especially for the quantum location. In effect, the dependency of $E_{\mathrm{g}}$ with size is demonstrated in the literature for ZnO nanoparticles. ${ }^{116,117}$ In contrast, when the crystal size is large, $E_{\mathrm{g}}$ tends to decrease because the Coulomb interaction plays a critical role in the change of $E_{\mathrm{g}}$ for crystals of larger sizes, which can explain the dependency of size on the $E_{\mathrm{g}}$ of large particles $(>100 \mathrm{~nm})$, which is the case in the present study.

\subsection{PL emission}

The PL property has always drawn attention from the scientific community, especially for the discovery of PL at room temperature, which favours its technological applications such as in LEDs, lasers in the visible light region and fibre optic components. ${ }^{119}$

The literature presents various models that explain this optical property, and among them, there is consensus that structural disorder is responsible for PL emission. A completely ordered or disordered material does not exhibit PL. Hence, a minimum order is necessary in a disordered system for the material to exhibit PL. ${ }^{\mathbf{1 2 0}}$

All the synthesised samples (figure not shown) exhibit very similar band profiles and positions in the non-standardised PL emission spectra. One emission band is observed in the violet range, located at approximately $400 \mathrm{~nm}$, with a small peak in the UV range approaching $380 \mathrm{~nm}$, and intense and highly superposed emission bands that range from 440 to $750 \mathrm{~nm}$ (blue to red emission), with a maximum at approximately $610 \mathrm{~nm}$.
PL is associated with the presence of structural disorder and is responsible for the formation of electronic levels within the band gap, i.e., the formation of energy levels between the valence band (VB) and conduction band (CB). The energy levels between the VB and $\mathrm{CB}$ can act as recombination centres for the electron-gap pair, promoting luminescence emission. Generally, $\mathrm{ZnO}$ crystals with the wurtzite structure of macroscopic dimensions (bulk) and crystal organisation approaching the ideal exhibit strong UV emission, whereas smaller crystals (micro and nanostructures) associated with the abundance of defects exhibit strong emissions in the visible region, where the modifications at the $\mathrm{ZnO}$ structure surface can increase or suppress the intensity and emission in the visible range. ${ }^{\mathbf{1 1 6}}$

The ratio of UV and visible emission intensities can be used to evaluate the quality of $\mathrm{ZnO} .{ }^{121}$ Generally, it is accepted that smaller ZnO crystal sizes are associated with PL emissions of low UV band ratios in relation to the visible band, caused by the large surface area and more surface defects. ${ }^{122}$ However, this tendency was not verified in the present study. Possibly, there is the formation of steps with crystal side surfaces larger than $\mathrm{ZnO}$, which may increase the surface/interface defects. Additionally, Zhou et al. (2002) suggest that for ZnO, intense emission bands in the visible range, more precisely above $500 \mathrm{~nm}$, can be attributed to the presence of $\mathrm{Zn}(\mathrm{OH})_{2}$ or $\mathrm{OH}^{-}$groups at the crystal surface level, which could also play the role of interstitial oxygen $\left(\mathrm{O}_{\mathrm{i}}\right)$. In other words, the excess of oxygen could lead to an increase of the number of defects in the crystal structure, elevating the intensity of the bands in the visible region. For the present study, where hydrothermal processing in alkaline $\mathrm{pH}$ is applied, this explanation is plausible for the observation of intense bands in the visible range, where hydroxyl groups or water at the surface can easily be present. ${ }^{123}$ This explanation would not necessarily be applicable to $\mathrm{ZnO}$ samples produced by other methods. Hence, the presence of the emission band in the visible region of the PL spectra for the samples produced in this study corroborates the Raman results. In the Raman spectra, a slight variation was observed in the characteristic positions of the vibration modes that could be related to a series of factors including the crystallinity degree, grain size distribution and average crystal size, ionic interaction force, degree of structural order and disorder in the crystal lattice, and presence of structural defects (oxygen vacancies, distortions or tensions in the structure). Thus, the size distribution in all the samples had a direct effect on the intensity of the emission bands and not on its appearance. This type of study involving the variation of the particle size and intensity of the emission band in the visible region of the PL spectrum has already been reported for $\mathrm{ZnO}$ samples on the micrometric scale synthesised at hydrothermal conditions in the absence of CTAB. ${ }^{\mathbf{1 2 4}}$ The variations of the positions observed in the Raman modes and the appearance of the emission band in the PL spectra are observed in this study, which is intimately related to the presence of defects created during the sample processing. Although there are many studies in the literature on the types of defects that cause such effects on different types of materials, a more detailed investigation is necessary to properly correlate the defect type and effect that are susceptible to the preparation 
conditions. Further studies are being performed to evaluate whether the defects in the samples produced in this study could be related to the presence of the $\mathrm{Zn}(\mathrm{OH})_{2}$ species or whether $\mathrm{OH}^{-}$groups could take the role of interstitial oxygen or whether the excess of oxygen in the reaction medium could be responsible for these changes of the $\mathrm{ZnO}$ characteristics.

\subsection{Catalytic activity}

Fig. 10 shows the photocatalytic activities of all samples for the degradation of $\mathrm{RhB}$ and $\mathrm{MO}$ aqueous solution under the simulative sunlight irradiation. The photocatalytic degradation of RhB as a function of time (Fig. 10a) was controlled of the $\mathrm{ZnO}$ samples obtained at different temperatures in the presence and absence of CTBA. The photolysis efficiency in absence of $\mathrm{ZnO}$ was less than $10 \%$ with irradiation for 90 minutes. The decolorization efficiencies of RhB degradation were $97 \%$, 92\% and $96 \%$ to $\mathrm{ZnO}$ obtained at 120,150 and $180^{\circ} \mathrm{C}$ in absence of CTBA, and $97 \%, 80 \%$ and $82 \%$ to $\mathrm{ZnO}$ obtained at 120,150 and $180{ }^{\circ} \mathrm{C}$ with CTBA. Comparing to $\mathrm{ZnO}$ obtained without CTBA with $\mathrm{ZnO}$ obtained in presence of CTBA, it showed the RhB decolorization of $97 \%$. Thus, the photocatalytic performance of the $\mathrm{ZnO}$ obtained at $120^{\circ} \mathrm{C}$ in absence of CTAB is the highest, decolorizing RhB at 40 minutes.

The photocatalytic degradation of MO as a function of time (Fig. 10b) was controlled of the $\mathrm{ZnO}$ samples obtained at different temperatures in the presence or absence of CTBA. The photolysis efficiency in absence of $\mathrm{ZnO}$ was less than $5 \%$ with irradiation for 90 minutes. The decolorization efficiencies of MB degradation were $99 \%, 63 \%$ and $82 \%$ to $\mathrm{ZnO}$ obtained at 120,150 and $180{ }^{\circ} \mathrm{C}$ in absence of CTBA, and 81\%, 58\% and $65 \%$ to $\mathrm{ZnO}$ obtained at 120,150 and $180{ }^{\circ} \mathrm{C}$ with CTBA. Comparing to $\mathrm{ZnO}$ obtained without and with CTBA, it is showed the MO decolorization of $99 \%$. Thus, the photocatalytic performance of the $\mathrm{ZnO}$ obtained at $120^{\circ} \mathrm{C}$ in presence of CTAB is the highest, decolorizing $\mathrm{MO}$ at 50 minutes.

The rate constant $k$ (Fig. 10c and d) can be calculated by the gradient of $\ln C_{t} / C_{0}=f(t)$ because the degradation follows a pseudo-first order kinetics. The $k$ value without catalyst equals $1.33 \times 10^{-3} \mathrm{~min}^{-1}$ and $0.51 \times 10^{-3} \mathrm{~min}^{-1}$ for degradation of $\mathrm{RhB}$ and MO, respectively. ZnO obtained without CTAB have $k$ values of $73.68 \times 10^{-3}$ (RhB degradation) and $85.16 \times 10^{-3}$ (MO degradation), using $\mathrm{ZnO}$ obtained at $120{ }^{\circ} \mathrm{C}$ (Z120, Fig. 10) as catalysts (Fig. 10c and d). Degradation with as little as $100 \mathrm{mg}$ of $\mathrm{ZnO}$ is more than 55 (RhB degradation) and more than 167 (MO degradation) times faster as without a catalyst. Compared to $\mathrm{ZnO}$ obtained in presence of CTAB, the catalyst obtained in absence (Zn120) are 2.0 times more efficient for degradation of $\mathrm{RhB}$, and 4.8 times more efficient for degradation of MO. From the kinetic analysis, it has been established that the degradation of RhB and MO follows first order kinetics with trends (a)

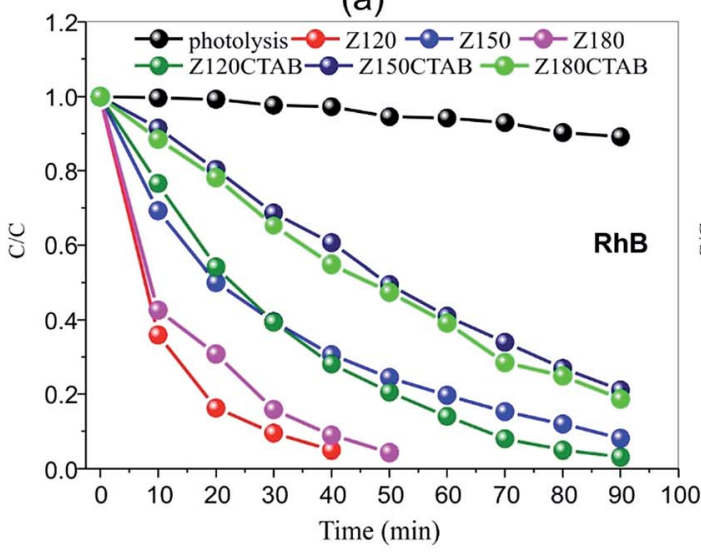

(C)

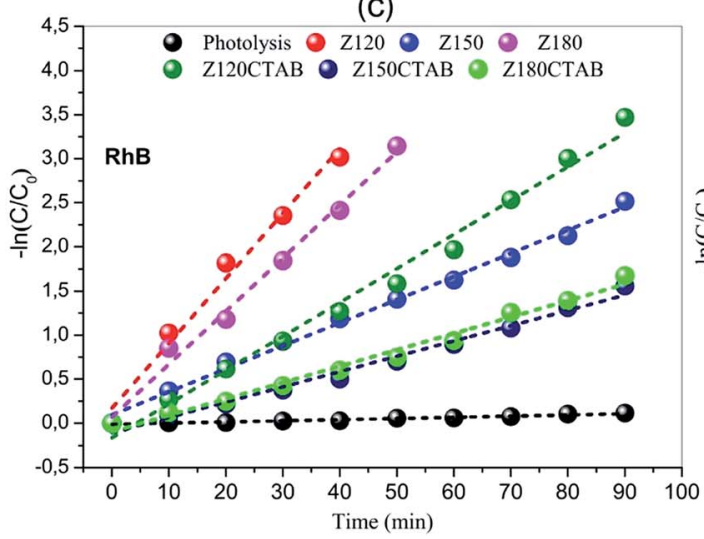

(b)

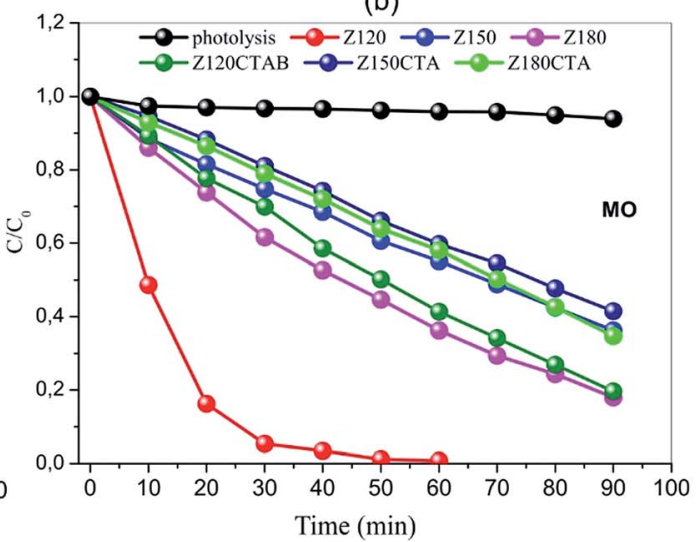

(d)

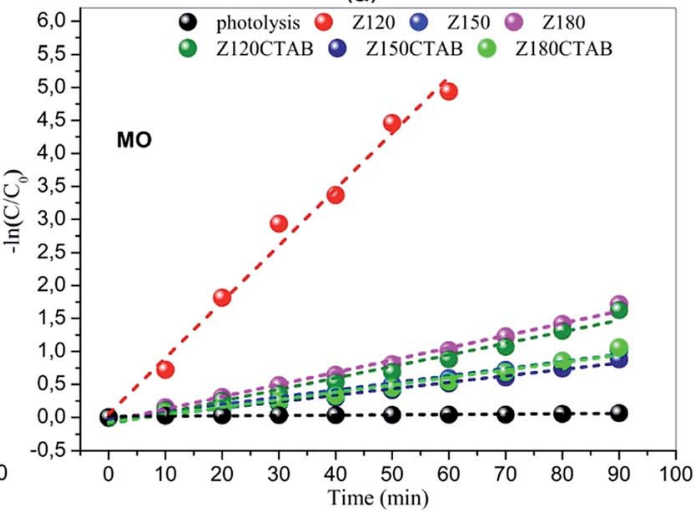

Fig. 10 Photocatalytic degradation of RhB and $M O$ ((a) and (b), respectively) and kinetic data fitting for the degradation of RhB and $M O$ ((c) and (d), respectively), using $\mathrm{ZnO}$ as catalyst. 
Table 6 Rate constants of pseudo-first order $(k)$ and half-life time $\left(t_{1 / 2}\right)$ for RhB and MO degradation with $\mathrm{ZnO}$ as catalyst

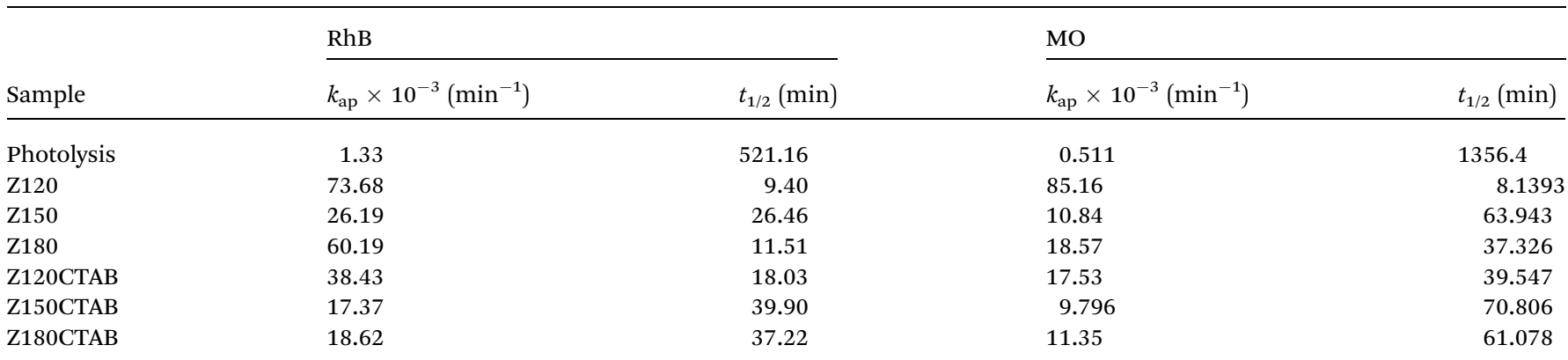

being displayed in Fig. 10 and the obtained values of kinetic rate constants given in Table 6 .

Intensive research work is being undertaken globally to effectively use the process of photocatalysis for the degradation of organic pollutants from industrial effluents. Many photocatalysts such as $\mathrm{TiO}_{2}, \mathrm{MoO}_{3}, \mathrm{SnO}_{2}, \mathrm{WO}_{3}, \mathrm{Fe}_{2} \mathrm{O}_{3}, \mathrm{Fe}_{3} \mathrm{O}_{4}$, $\mathrm{Ag}_{2} \mathrm{WO}_{4}, \mathrm{Ag}_{2} \mathrm{MO}_{4}$, etc. and combinations thereof, have been extensively investigated as suitable materials for pollutant degradation under UV/visible/solar light. ${ }^{125-133}$ In general, several authors clearly show that morphology, and principally, both a high degree of crystallinity and moderate surface area are necessary to obtain highly active materials for organic pollutants degradation. The results obtained in this work are in good agreement with previous reports. ${ }^{134-136} \mathrm{ZnO}$ formed by the hydrothermal method exhibit high catalytic activity (Fig. 10).

\section{Conclusion}

The present study demonstrated that ZnO microcrystals with narrow size distributions can be successfully synthesised with chemical reproducibility in the wurtzite phase with the form of hexagonal columns starting from zinc acetate in alkaline medium at 120,150 and $180^{\circ} \mathrm{C}$ with and without the assistance of CTAB. The developed method is simple, allows for the production of ZnO microstructures in just $24 \mathrm{~h}$ of processing and uses common lowcost experimental apparatus, which is promising for industrialscale application. Furthermore, the method offers control of the structural properties of the $\mathrm{ZnO}$ microcrystals by the appropriate selection of the reaction temperature, $\mathrm{pH}$ and the presence or absence of CTAB. These variables allow differentiated $\mathrm{ZnO}$ microcrystals to be prepared to meet the requirements of different technological applications. Photocatalytic degradation under UV irradiation reduced effectively the $\mathrm{RhB}$ and $\mathrm{MO}$, with the best degradation results obtained for $\mathrm{ZnO}$ obtained at $120{ }^{\circ} \mathrm{C}$ and absence of CTAB. The differential of this work is the $\mathrm{ZnO}$ obtained from hydrothermal method, which can be easily separated from the solution using a simple filtration system with common filter paper, thus contributing to sustainable development and economically viable for industrial application, maintaining the high photocatalytic activity.

\section{Acknowledgements}

The authors would like to acknowledge the support provided by the Federal University of Piauí (Universidade Federal do Piauí -
UFPI), the Laboratory of Nanocharacterisation of the Federal University of São Carlos (Universidade Federal de São Carlos UFSCar), the São Paulo Research Foundation (Fundação de Amparo à Pesquisa do Estado de São Paulo - FAPESP) 2012/ 19926-8, the National Council for Scientific and Technological Development (Conselho Nacional de Desenvolvimento Científico e Tecnológico - CNPq) 473669/2012-9 and the Northeast Centre for Strategic Technologies (Centro de Tecnologias Estratégicas do Nordeste - CETENE).

\section{References}

1 Z. L. Wang, J. Phys.: Condens. Matter, 2004, 16, R829-R858. 2 K. Choi, T. Kang and S. G. Oh, Mater. Lett., 2012, 75, 240-243.

3 Y. Masuda, N. Kinoshita, F. Sato and K. Koumoto, Cryst. Growth Des., 2006, 6, 75-78.

4 P. F. Carcia, R. S. Mclean and M. H. Reilly, Appl. Phys. Lett., 2006, 88, 1235091-1235093.

5 A. Stankovic, Z. Stojanovic, L. Veselinovic, S. D. Skapin, I. Bracko, S. Markovic and D. Uskokovic, Mater. Sci. Eng., B, 2012, 177, 1038-1104.

6 S. Baruah and J. Dutta, Sci. Technol. Adv. Mater., 2009, 10, 013001.

7 R. Zhang, S. Kumar, S. Zou and L. L. Kerr, Cryst. Growth Des., 2008, 8, 381-383.

8 X. Zhao, W. Liu, R. Chen, Y. Gao, B. Zhu, H. V. Demir, S. Wang and H. Sun, Nanoscale, 2016, 8(11), 5835-5841.

9 X. Zhang, S. Yang, S. Bi, A. Kumaresan, J. Zhou, J. Seifter, H. Mi, Y. Xu, Y. Zhang and H. Zhou, RSC Adv., 2017, 7, 12400-12406.

10 W. L. Suchanek, J. Cryst. Growth, 2009, 312, 100-108.

11 Y. Yang, G. Du, X. Xin and B. Xu, Appl. Phys. A, 2011, 104, 1229-1235.

12 S. Ekambaram, J. Alloys Compd., 2005, 390, L4-L6.

13 K. Byrappa, A. K. Subramani, S. Ananda, K. M. L. Rai, R. Dinesh and M. Yoshimura, Bull. Mater. Sci., 2006, 29, 433-438.

14 Y. Sun, L. Chen, Y. Bao, Y. Zhang, J. Wang, M. Fu, J. Wu and D. Ye, Catalysts, 2016, 6(12), 18891-18944.

15 K. Schilling, B. Bradford, D. Castelli, E. Dufour, J. F. Nash, W. Pape, S. Schulte, I. Tooley, J. V. D. Boschi and F. Schellauf, Photochem. Photobiol. Sci., 2010, 9, 495-509.

16 P. Rai, S. K. Tripathy, N. H. Park, O. Kwang-Joong, I. H. Lee and Y. T. Yu, J. Mater. Sci.: Mater. Electron., 2009, 20, 967971. 
17 A. Ammala, A. J. Hill, P. Meakin, S. J. Pas and T. W. J. Turney, J. Nanopart. Res., 2002, 4, 167-174.

18 M. H. Lai, A. Tubtimtae, M. W. Lee and G. J. Wang, Int. J. Photoenergy, 2010, 497095.

19 A. K. Barui, V. Veeriah, S. Mukherjee, J. Manna, A. K. Patel, S. Patra, K. Pal, S. Murali, R. K. Rana, S. Chatterjee and C. R. Patra, Nanoscale, 2012, 4, 7861-7869.

20 I. M. M. Paino, F. J. Gonçalves, F. L. Souza and V. Zucolotto, ACS Appl. Mater. Interfaces, 2016, 8, 32699-32705.

21 A. Moezzi, A. M. Mcdonagh and M. B. Cortie, Chem. Eng. J., 2012, 185-186, 1-22.

22 S. Bhushan, ed. D. R. Vij and N. Singh, Materials Letters, Zinc oxide Nova Science Publishers Inc., Commack Ny, 1998.

23 M. J. Height, L. Madler, S. E. Pratsinis and F. Krumeich, Chem. Mater., 2006, 18, 572-578.

24 M. A. Tshabalala, B. F. Dejene and H. C. Swart, Physica B, 2012, 407, 1668-1671.

25 Y. W. Chen, Q. Qiao, Y. C. Liu and G. L. Yang, J. Phys. Chem. C, 2009, 113, 7497-7502.

26 S. Music, D. Dragcevic and S. Popovic, Mater. Lett., 2005, 59, 2388-2393.

27 H. Tang, J. C. Chang, Y. Shan and S. T. Lee, J. Phys. Chem. B, 2008, 112, 4016-4021.

28 M. Yoshimura and K. Byrappa, J. Mater. Sci., 2008, 43, 20852103.

29 K. Byrappa and T. Adschiri, Prog. Cryst. Growth Charact. Mater., 2007, 53, 117-166.

30 N. Tiwale, Sens. Actuators, B, 2014, 204, 250-272; D. Ju, H. Xu, J. Zhang, J. Guo and B. Cao, Sens. Actuators, B, 2014, 201, 444-451.

31 N. Tiwale, Mater. Sci. Technol., 2015, 31(14), 1681-1697.

32 K. F. Cai, X. R. He and L. C. Zhang, Mater. Lett., 2008, 62, 1223-1225.

33 J. Zhan, H. Dong, Y. Liu, Y. Wang, Z. Chen and L. Zhang, CrystEngComm, 2013, 15, 10272-10277.

34 J. Wang, R. Chen, Y. Xia, G. Wang, H. Zhao, L. Xiang and S. Komarneni, Ceram. Int., 2017, 43, 1870-1879.

35 K. N. Abbas and N. Bidin, Appl. Surf. Sci., 2017, 394, 498508.

36 X. Zheng, R. Wu and Y. Chen, Environ. Sci. Technol., 2011, 45, 2826-2832.

37 N.-Q. Puay, G. Qiu and Y.-P. Ting, J. Cleaner Prod., 2015, 88, 139-145.

38 J. Choi, S. Chan, H. Joo, H. Yang and F. K. Ko, Water Res., 2016, 101, 362-369.

39 B. G. Wang, E. W. Shi and W. Z. Zhong, Cryst. Res. Technol., 1998, 33, 937-941.

40 C. Y. Toe, H. L. Tan, C. Boyer, A. Rawal, S. C. Thickett, J. Scott, R. Amal and Y. H. Ng, J. Mater. Chem. A, 2017, 5, 4568-4575.

41 Y. Liu, X. Yan, Z. Kang, Y. Li, Y. Shen, Y. Sun, L. Wang and Y. Zhang, Sci. Rep., 2016, 6, 1-7.

42 J. S. Souza, W. M. Carvalho, F. L. Souza, C. Ponce-de-Leon, D. V. Bavykin and W. A. Alves, J. Mater. Chem. A, 2016, 4, 944-952.
43 S. Adhikari, D. Sarkar and G. Madras, RSC Adv., 2014, 4, 55807-55814.

44 Y. Fang, Z. Li, S. Xu, D. Han and D. Lu, J. Alloys Compd., 2013, 575, 359-363.

45 L. Wolski, J. E. Whitten, I. Sobczak and M. Ziolek, Mater. Res. Bull., 2017, 85, 35-46.

46 Y. X. Wang, J. Sun, X. A. Fan and X. Yu, Ceram. Int., 2011, 37, 3431-3436.

47 H. Kato, K. Miyamoto and M. Sano, Appl. Phys. Lett., 2004, 4, 4562-4564.

48 M. Anbuvannan, M. Ramesh, G. Viruthagiri, N. Shanmugam and N. Kannadasan, Spectrochim. Acta, Part A, 2015, 143, 304-308.

49 H. Schulz and K. H. Thiemann, Solid State Commun., 1979, 32, 783-785.

$50 \mathrm{http}: / / w w w . p o r t a l d a p e s q u i s a . c o m . b r$, accessed in 11-062016.

51 Y. Chen, R. Yu, Q. Shi, J. Qina and F. Zheng, Mater. Lett., 2007, 61, 4438-4441.

52 G. Sun, M. Cao, Y. Wang, C. Hu, Y. Liu, L. Ren and Z. Pu, Mater. Lett., 2006, 60, 2777-2782.

53 C. Jiang, W. Zhang, G. Zou, W. Yu and Y. Qian, J. Phys. Chem. B, 2005, 109, 1361-1361.

54 Y. H. Ni, X. W. Wei, J. M. Hong and Y. Ye, Mater. Sci. Eng., B, 2005, 121, 42-47.

55 A. P. A. Oliveira, J. F. Hochepied, F. Grillon and M. H. Berger, Chem. Mater., 2003, 15, 3202-3207.

56 S. C. Abrahams and J. L. Bernstein, Acta Crystallogr., Sect. B: Struct. Sci., 1969, 25, 1233-1236.

57 K. Kiharai and G. Donnay, Can. Mineral., 1985, 23, 647-654.

58 L. B. Mccusker, R. B. V. Dreele, D. E. Cox, D. Louër and P. Scardi, J. Appl. Crystallogr., 1999, 32, 36-50.

59 J. M. A. Almeida, C. T. Meneses, A. S. Menezes, R. F. Jardim and J. M. Sasaki, Magn. Magn. Mater., 2008, 320, 304-307.

60 R. A. Young, The Rietveld Method, Oxford University Press, New York, 1995.

$61 \mathrm{http}: / /$ www.crystalimpact.com/diamond, accessed in in 1309-2016.

62 Ü. Özgür, Y. I. Alivov, C. Liu, A. Tekeb, M. A. Reshchikov, S. Doğan, V. Avrutin, S.-J. Cho and H. Morkoç, J. Appl. Phys., 2005, 98, 041301.

63 M. Koyano, P. Quocbao, L. T. Thanhbinh, L. Hongha, N. Ngoclong and S. Katayama, Phys. Status Solidi A, 2002, 193, 125-131.

64 K. Mcguire, Z. W. Pan, Z. L. Wang, D. Milkie, J. Menéndez and A. M. Rao, J. Nanosci. Nanotechnol., 2002, 2, 499-502.

65 S. B. Yahia, L. Znaidi, A. Kanaev and J. P. Petitet, Spectrochim. Acta, Part A, 2008, 71, 1234-1238.

66 Y. Huang, M. Liu, Z. Li, Y. Zeng and S. Liu, J. Mater. Sci. Eng. $B, 2003,97,111-116$.

67 R. S. Yadav and A. C. Pandey, Struct. Chem., 2009, 20, 10931097.

68 A. P. Moura, R. C. Lima, M. L. Moreira, D. P. Volanti, J. W. M. Espinosa, M. O. Orlandi, P. S. Pizani, J. A. Varela and E. Longo, Solid State Ionics, 2010, 181, 775-780.

69 N. Ashkenov, B. N. Mbenkum, C. Bundesmann, V. Riede, M. Lorenz, D. Spemann, E. M. Kaidashev, A. Kasic, 
M. Schubert, M. Grundmann, G. Wagner, H. Neumann, V. Darakchieva, H. Arwin and B. Monemar, J. Appl. Phys, 2003, 93, 126-133.

70 T. C. Damen, S. P. S. Porto and B. Tell, Phys. Rev., 1966, 142, 570-574.

71 C. A. Arguello, D. L. Rousseau and S. P. S. Porto, Phys. Rev., 1969, 181, 1351-1363.

72 M. Tsuboi and A. Wada, J. Chem. Phys., 1968, 48, 2615-2618.

73 A. Zaoui and W. Sekkal, Phys. Rev. B: Condens. Matter Mater. Phys., 2002, 66, 1741061-1741066.

74 R. Jothilakshmi, V. Ramakrishnan, R. Thangavel, J. Kumar, A. Sarua and M. Kuball, J. Raman Spectrosc., 2009, 40, 556561.

75 R. Cuscó, E. Alarcón-Lladó, J. Ibáñez, L. Artús, J. Jiménez, B. Wang and M. Callahan, J. Phys. Rev. B, 2007, 75, 165202-165207.

76 J. Zhao, X. Yan, Y. Yang, Y. Huang and Y. Zhang, Mater. Lett., 2010, 64, 569-572.

77 L. N. Dem'yanets, D. V. Kostomarov and I. P. Kuz'mina, Inorg. Mater., 2002, 38, 124-131.

78 X. Liu, X. Wu, H. Cao and R. P. H. Chang, J. Appl. Phys., 2004, 95, 3141-3147.

79 N. U. Sangari and S. C. Devi, J. Solid State Chem., 2013, 197, 483-488.

80 A. Becheri, M. Durr, P. L. Nostro and P. Baglioni, J. Nanopart. Res., 2008, 10, 679-689.

81 S. Maensiria, P. Laokula and V. Promarak, J. Cryst. Growth, 2006, 289, 102-106.

82 E. F. Venger, A. V. Melnichuk, L. Y. Melnichuk and Y. A. Pasechnik, Phys. Status Solidi B, 1995, 188, 823-831.

83 F. Li, L. Hu, Z. Li and X. Huang, J. Alloys Compd., 2008, 465, l14-119.

84 H. X. Niu, Q. Yang, F. Yu, K. B. Tang and Y. Xie, Mater. Lett., 2007, 61, 137-140.

85 X. Jiang, Y. Liu, Y. Gao, X. Zhang and L. Shi, Particuology, 2010, 8, 383-385.

86 X. Gao, X. Li and W. Yu, J. Phys. Chem. B, 2005, 109, 11551161.

87 S. D. Shinde, G. E. Patil, D. D. Kajale, D. V. Ahire, V. B. Gaikwad and G. H. Jain, Int. J. Smart Sensing and Intell. Systems, 2012, 5, 57-70.

88 H. Zhang, D. Yang, X. Ma, Y. Ji, J. Xu and D. Que, J. Nanotechnol., 2004, 15, 622-626.

89 X. M. Sun, X. Chen, Z. X. Deng and Y. D. Li, Mater. Chem. Phys., 2002, 78, 99-103.

90 H. Zhang, D. Yang, Y. Ji, X. Ma, J. Xu and D. Que, J. Phys. Chem. B, 2004, 108, 3955-3958.

91 U. N. Maiti, S. Nandy, S. Karan, B. Mallik and K. K. Chattopadhyay, Appl. Surf. Sci., 2008, 254, 7266-7271.

92 Y. Liu, H. Lv, S. Li, G. Xi and X. Xing, Adv. Powder Technol., 2011, 22, 784-788.

93 Y. H. Ni, X. W. Wei, X. Ma and J. M. Hong, J. Cryst. Growth, 2005, 283, 48-56.

94 J. Ge, B. Tang, L. Zhuo and Z. Shi, J. Nanotechnol., 2006, 17, 1316-1322.

95 X. P. Gao, Z. F. Zheng, H. Y. Zhu, G. L. Pan, J. L. Bao, F. Wu and D. Y. Song, Chem. Commun., 2004, 1428-1429.
96 M. Bitenc, G. Drazic and Z. C. Orel, Cryst. Growth Des., 2010, 10, 830-837.

97 B. G. Wang, E. W. Shi and W. Z. Zhong, Cryst. Res. Technol., 1997, 32, 659-667.

98 S. C. Zhang and X. G. Li, Colloids Surf., 2003, 35-44.

99 L. N. Dem'yanets, D. V. Kostomarov and I. P. Kuz'mina, Inorg. Mater., 2002, 38, 124-131.

100 C. L. Kuo, T. J. Kuo and M. H. Huang, J. Phys. Chem. B, 2005, 109, 20115-20121.

101 B. G. Wang, E. W. Shi and W. Z. Zhong, Cryst. Res. Technol., 1998, 33, 937-941.

102 P. Kubelka and F. Munk-Aussig, Zeit. Fur. Tech. Physik, 1931, 12, 593-599.

103 P. J. A. Porn, S. Suwanboon and P. J. Amornpitoksuk, J. Ceram. Process. Res., 2011, 12, 85-89.

104 Y. Huo and Y. H. Hu, Ind. Eng. Chem. Res., 2012, 51, 10831085.

105 R. Rusdi, A. A. Rahman, N. S. Mohamed, N. Kamarudin and N. Kamarulzaman, Powder Technol., 2011, 210, 18-22.

106 S. Suwanboon, P. Amornpitoksuk and S. Muensit, J. Ceram. Process. Res., 2010, 11, 419-424.

107 T. V. Kolekar, H. M. Y. Adav, S. S. A. Bandgar, A. C. Raskar, S. G. Rawal and G. M. Mishra, Indian Streams Res. J., 2011, 2, 1-3.

108 Y. Tong, L. Dong, Y. Liu, D. Zhao, J. Zhang, Y. Lu, D. Shen and X. Fan, Mater. Lett., 2007, 61, 3578-3581.

109 K. F. Lin, H. M. Cheng, H. C. Hsu, L. J. Lin and H. F. Hsieh, Chem. Phys. Lett., 2005, 409, 208-211.

110 D. C. Look, C. R. Donald, J. R. Sizelove, R. L. Jones, C. W. Litton, G. Cantwell and W. C. Harsch, Solid State Commun., 1998, 105, 399-401.

111 A. J. Hauser, J. Zhang, L. Mier, R. A. Ricciardo, P. M. Woodward, T. L. Gustafson, L. J. Brillson and F. Y. Yang, Appl. Phys. Lett., 2008, 92, 22290.

112 J. J. Thevaril and S. K. O'leary, Solid State Commun., 2010, 150, 1851-18555.

113 K. Sakai, T. Kakeno, T. Ikari, S. Shirakata, T. Sakemi, K. Awai and T. Yamamoto, J. Appl. Phys., 2006, 99, 043508.

114 R. E. Marotti, P. Giorgi, G. Machado and E. A. Dalchiele, Sol. Energy Mater. Sol. Cells, 2006, 90, 2356-2361.

115 J. Y. Kang, S. Tsunekawa and A. Kasuya, Acta Phys. Sinica, 2001, 50, 2198-2205.

116 L. Zhang, L. Yin, C. Wang, N. Lun, Y. Qi and D. Xiang, J. Phys. Chem. C, 2010, 114, 9651-9658.

117 U. Koch, A. Fojtik, H. Weller and A. Henglein, Chem. Phys. Lett., 1985, 122, 507-510.

118 L. Brus, J. Phys. Chem., 1986, 90, 2555-2560.

119 P. R. Lucena, F. M. Pontes, C. D. Pinheiro, E. Longo, P. S. Pizani, S. Lázaro, A. G. Souza and I. M. G. Santos, Ceramica, 2004, 50, 138-144.

120 G. Blasse and B. C. Grabmaier, Luminescent Materials, Springer-Verlag, Berlin, 1994.

121 M. Izaki, T. Shinagawa and H. Takahashi, J. Phys. D: Appl. Phys., 2006, 39, 1481-1484.

122 B. D. Yao, Y. F. Chan and N. Wang, Appl. Phys. Lett., 2002, 81, 757-759. 
123 A. B. Djurisic, Y. H. Leung, K. H. Tam, Y. F. Hsu, L. Ding, W. K. Ge, Y. C. Zhong, K. S. Wong, W. K. Chan, H. L. Tam, K. W. Cheah, W. M. Kwok and D. L. Phillips, J. Nanotechnol., 2007, 18, 095702.

124 S. Duo, Y. Li, Z. Liu, R. Zhong and T. Liu, J. Alloys Compd., 2017, 695, 2563-2579.

125 L. V. Bora and R. K. Mewada, Renewable Sustainable Energy Rev., 2017, 76, 1393-1421.

126 J. Ni, J. Gao, X. Geng, D. He and X. Guo, Appl. Phys. A: Mater. Sci. Process., 2017, 123, 186.

127 H. Liu, T. Lv, C. Zhu and Zh. Zhu, Sol. Energy Mater. Sol. Cells, 2016, 153, 1-8.

128 E. Pervaiz, H. Liu and M. Yang, Nanotechnology, 2017, 28, 105701.

129 S. Garcia-Segura and E. Brillas, J. Photochem. Photobiol., C, 2017, 31, 1-35.
130 S. G. Kumar and K. S. R. K. Rao, Appl. Surf. Sci., 2017, 391, 124-148.

131 J. Wang, Y. Chen, G. Liu and Y. Cao, Composites, Part B, 2017, 114, 211-222.

132 Z. Wang, K. Dai, C. Liang, J. Zhang and G. Zhu, Mater. Lett., 2017, 196, 373-376.

133 Z. Lin, J. Li, Z. Zheng, J. Yan, P. Liu, Ch. Wang and G. W. Yang, ACS Nano, 2015, 9, 7256-7265.

134 L. V. Bora and R. K. Mewada, Renewable Sustainable Energy Rev., 2017, 76, 1393-1421.

135 M. Pelaez, N. T. Nolan, S. C. Pillai, M. K. Seery, P. Falaras, A. G. Kontos, P. S. M. Dunlop, J. W. J. Hamilton, J. A. Byrne, K. O'Shea, M. H. Entezari and D. D. Dionysiou, Appl. Catal., B, 2012, 125, 331-349.

136 J. G. McEvoy and Z. Zhang, J. Photochem. Photobiol., C, 2014, 19, 62-75. 